\title{
Differential Response of Digesta- and Mucosa-Associated Intestinal Microbiota to Dietary Black Soldier Fly (Hermetia illucens) Larvae Meal in Seawater Phase Atlantic Salmon (Salmo salar)
}

\author{
${ }^{1}$ Department of Paraclinical Sciences, Norwegian University of Life Sciences, Oslo, Norway \\ ${ }^{2}$ Department of Agriculture, Food, Environment and Forestry, University of Florence, Firenze, Italy \\ ${ }^{3}$ Present address: Biomar AS, Havnegata 9, 7010 Trondheim, Norway \\ ${ }^{*}$ These authors contributed equally.
}

Yanxian $\mathbf{L i}^{1}{ }^{*} \bowtie$, Leonardo Bruni $^{2}{ }^{*}$, Alexander Jaramillo-Torres ${ }^{1}$, Karina Gajardo $^{1,3}$, Trond M. Kortner $^{1}$, and Åshild Krogdahl ${ }^{1}$

\begin{abstract}
Intestinal digesta is commonly used for studying responses of microbiota to dietary shifts, yet evidence is accumulating that it represents an incomplete view of the intestinal microbiota. In a 16-week seawater feeding trial, Atlantic salmon (Salmo salar) were fed either a commercially-relevant reference diet or an insect meal diet containing $15 \%$ black soldier fly (Hermetia illucens) larvae meal. The digesta- and mucosa-associated distal intestinal microbiota were profiled by $16 \mathrm{~S}$ rRNA gene sequencing. Regardless of diet, we observed substantial differences between digesta- and mucosa-associated intestinal microbiota. Microbial richness and diversity were much higher in the digesta than the mucosa. The insect meal diet altered the distal intestinal microbiota resulting in higher microbial richness and diversity. The diet effect, however, depended on the sample origin. Digesta-associated intestinal microbiota showed more pronounced changes than the mucosa-associated microbiota. Lastly, multivariate association analyses identified two mucosa-enriched taxa, Brevinema andersonii and unclassified Spirochaetaceae, associated with the expression of genes related to immune responses and barrier function in the distal intestine, respectively. Overall, our data clearly indicate that responses in digesta- and mucosa-associated microbiota to dietary inclusion of insect meal differ, with the latter being more resilient to dietary changes.
\end{abstract}

Microbiota | Gut biogeography | Atlantic salmon | Diet | Black soldier fly Correspondence: yanxianı@nmbu.no

\section{Introduction}

The reduction in the sequencing costs and the advent of bioinformatics in the past decade have enabled in-depth taxonomic and functional profiling of microbial communities from diverse environments at an unprecedented scale. Recent advances in the microbiome studies have shed light on the role of intestinal microbiota in a wide spectrum of host physiological processes and development of diseases, such as helping digestion and absorption (1), modulating lipid metabolism and energy balance $(2,3)$, dialoguing with the central nervous system through the so-called microbiota-gut-brain axis
(4) and being a risk factor or a therapeutic intervention of inflammatory bowel disease (5-8). Diet is one of the key factors in shaping the intestinal microbiota. While long-term dietary habits have a considerable effect on the structure and activity of host intestinal microbiota (9-11), short-term dietary change also alters the intestinal microbiota in a rapid and reproducible way (12). Different dietary components selectively promote or suppress the growth of certain microbial clades, which in turn could inflict important effects on the host health and disease resistance $(13,14)$.

Atlantic salmon (Salmo salar) is the most produced seawater fish species and one of the most economically important farmed fish worldwide (15). While Atlantic salmon are strictly carnivorous in the wild, farmed Atlantic salmon have experienced a substantial shift in the diet composition due to a limited supply of marine ingredients. Marine ingredients used for Norwegian farmed Atlantic salmon have gradually been replaced by plant sources, decreasing from $90 \%$ in 1990 to $25 \%$ in 2016 (16). Due to concerns on the economic, environmental and social sustainability of the current raw materials for Atlantic salmon farming (15), more sustainable alternative feed ingredients, such as insects (17) and yeasts (18), have been developed and used. The use of alternative feed ingredients may not only affect the nutrient utilization, fish growth, health, welfare and product quality, but also intestinal microbiota in Atlantic salmon (19-21). While studies in mammals and fish have revealed substantial differences between the digesta- and mucosa-associated intestinal microbiota $(19,22-25)$, most studies investigating diet effects on the intestinal microbiota of fish have sampled the digesta only or a mixture of digesta and mucosa. Evidence is accumulating that digesta- and mucosa-associated intestinal microbiota in fish respond differently to dietary changes (19, 26-29). Profiling only one of or a mixture of digestaand mucosa-associated microbiota may obscure the response of intestinal microbiota to dietary changes.

Characterizing intestinal microbiota and its associations 
with host responses is an essential step towards identifying key microbial clades promoting fish health and welfare. Ultimately, a milestone in the fish microbiota research would be knowing how to selectively manipulate the microbiota to improve the growth performance, disease resistance and health status of farmed fish. The main aims of the work presented herein were (i) to compare distal intestinal microbiota of Atlantic salmon fed a commercially relevant diet and an insect meal-based diet, (ii) to further explore the dissimilarity between digesta- and mucosa-associated microbiota and the differences in their response to dietary changes, and (iii) to identify associations between microbial clades and host responses. This work was part of a larger study consisting of a freshwater and seawater feeding trial that aimed to investigate the nutritional value and possible health effects for Atlantic salmon of a protein-rich insect meal produced from black soldier fly (Hermetia illucens) larvae. The present work focuses on the intestinal microbiota in seawater phase Atlantic salmon fed an insect meal diet containing 15\% black soldier fly larvae meal for 16 weeks. Results on feed utilization, growth performance, fillet quality, intestinal histomorphology and gene expression have been reported elsewhere (30-32).

\section{Results}

Hereafter, different sample groups are named based on the combination of diet (REF vs. IM) and sample origin (DID vs. DIM). Hence, in addition to the extraction blanks, library blanks and mock, we have four different sample types, i.e., REF-DID, REF-DIM, IM-DID and IM-DIM.

qPCR. Since Cq values of most mucosa DNA templates were out of the linear range of the standard curve, the raw $\mathrm{Cq}$ value was used as a proxy of 16S rRNA gene quantity in the diluted DNA templates (Fig. S1). On average, REF-DID showed the highest 16S rRNA gene quantities (mean $\mathrm{Cq}=24.7$ ), followed by the mock (mean $\mathrm{Cq}=26.1$ ) and IM-DID (mean Cq = 28.4). Irrespective of diet, mucosa DNA templates (REFDIM, IM-DIM) showed similar 16S rRNA gene quantities (mean $\mathrm{Cq}=30$ ) that were close to extraction blanks (mean $\mathrm{Cq}=32.4)$.

Taxonomic composition. All the eight bacterial species included in the mock were successfully identified at genus level with Enterococcus faecalis, Lactobacillus fermentum, Listeria monocytogenes and Staphylococcus aureus further being annotated at the species level (Fig. S2A). At the genus level, the average Pearson's $r$ between the expected and observed taxonomic profile of the mock was 0.33 , whereas the Pearson's $r$ between the observed taxonomic profile of the mock was 0.98 . The relative abundance of most Grampositive bacteria, Listeria monocytogenesand Enterococcus faecalis in particular, were underestimated. In contrast, the relative abundance of Gram-negative bacteria was overestimated. Most ASVs (97.5\% - 99.9\%) in the extraction and library blanks were classified as Pseudomonas (Fig. S2B), which was the main contaminating taxon removed from the biological samples along with other contaminants including Curtobacterium, Jeotgalicoccus, Modestobacter, Cutibacterium, Hymenobacter, Brevundimonas, Micrococcus, Sphingomonas, Devosia, Sphingomonas aurantiaca and Marinobacter adhaerens. The exact sequence of the contaminating ASVs and their relative abundance in the extraction and library blanks are available in Table S1.

The taxonomic composition of mucosa samples showed higher similarity than that of the digesta samples, which were more diet-dependent (Fig. 1). At the phylum level, the dominant taxa of mucosa samples for both diets were Spirochaetes (REF-DIM, $72 \pm 34.6 \%$; IM-DIM, $47 \pm 35.2 \%$ ) (mean \pm S.D.), Proteobacteria (REF-DIM, $21 \pm 34.1 \%$; IM-DIM, 23 $\pm 34.1 \%$ ), Firmicutes (REF-DIM, $1 \pm 2.8 \%$; IM-DIM, $11 \pm$ $13.5 \%$ ), Tenericutes (REF-DIM, $4 \pm 8 \%$; IM-DIM, $8 \pm 18.8$ $\%$ ) and Actinobacteria (REF-DIM, $1 \pm 3.4 \%$; IM-DIM, $9 \pm$ $8.7 \%)$. For digesta samples, the dominant taxa of REF-DID were Tenericutes $(33 \pm 23.1 \%)$, Proteobacteria $(31 \pm 29.9$ $\%)$, Firmicutes $(25 \pm 21.1 \%)$ and Spirochaetes $(9 \pm 12.9 \%)$, whereas IM-DID was dominated by Firmicutes ( $45 \pm 16.9$ $\%)$, Actinobacteria $(25 \pm 9.5 \%)$, Proteobacteria $(17 \pm 27.8$ $\%)$, Tenericutes $(7 \pm 8.8 \%)$ and RsaHF231 (4 $\pm 1.5 \%)$ (Fig. 1A). At the genus level, the dominant taxa of mucosa samples for both diets were Brevinema (REF-DIM, $52 \pm 40.1 \%$; IMDIM, $25 \pm 35 \%$ ), unclassified Spirochaetaceae (REF-DIM, $20 \pm 31.8 \%$; IM-DIM, $22 \pm 31.4 \%$ ), Aliivibrio (REF-DIM, $18 \pm 33.5 \%$; IM-DIM, $18 \pm 35.3 \%$ ) and Mycoplasma (REFDIM, $4 \pm 8 \%$; IM-DIM, $8 \pm 18.8 \%$ ). For digesta samples, the dominant taxa of REF-DID were Mycoplasma (33 \pm 23.1 $\%)$, Aliivibrio $(20 \pm 32.3 \%)$, Photobacterium (10 $\pm 12.6 \%)$, Brevinema $(6 \pm 12.5 \%)$ and Lactobacillus $(5 \pm 4 \%)$, whereas IM-DID was dominated by Aliivibrio $(15 \pm 28.2 \%)$, unclassified Lactobacillales (14 $\pm 6 \%)$, Corynebacterium 1 (13 \pm $5 \%)$, Bacillus $(8 \pm 3.4 \%)$, Mycoplasma $(7 \pm 8.8 \%)$ and Actinomyces (5 $\pm 2 \%$ ) (Fig. 1B).

Core microbiota. In total, 108 taxa were identified as core microbiota based on their prevalence in each sample type (Fig.2; Table S2). Specifically, Aliivibrio, Brevinema andersonii, and Mycoplasma were identified as core microbiota for all the sample types, the latter two being universally present in all the samples. Additionally, ten taxa were identified as core microbiota for digesta samples (REF-DID and IM-DID), which included Bacillus, Corynebacterium 1, Lactobacillus (L. aviaries, L. fermentum and two unclassified species), Leuconostoc, Parageobacillus toebii, Ureibacillus and Weissella. No additional core microbiota taxa were identified for the mucosa samples (REF-DIM and IM-DIM). Actinomyces, Corynebacterium 1, Corynebacterium aurimucosum ATCC 70097, Microbacterium and unclassified RsaHF23 were the additional core microbiota taxa identified for fish fed the insect meal diet (IM-DID and IM-DIM), whereas no additional core microbiota taxa were identified for fish fed the reference diet (REF-DID and REF-DIM). Lastly, 86 taxa were found to be more prevalent in IM-DID than in any other sample type.

Alpha-diversity. Regardless of diet, all the alpha-diversity indices were higher in digesta samples than mucosa samples 
bioRxiv preprint doi: https://doi.org/10.1101/2020.05.08.083899; this version posted May 24, 2020. The copyright holder for this preprint (which was not certified by peer review) is the author/funder, who has granted bioRxiv a license to display the preprint in perpetuity. It is made available under aCC-BY-ND 4.0 International license.
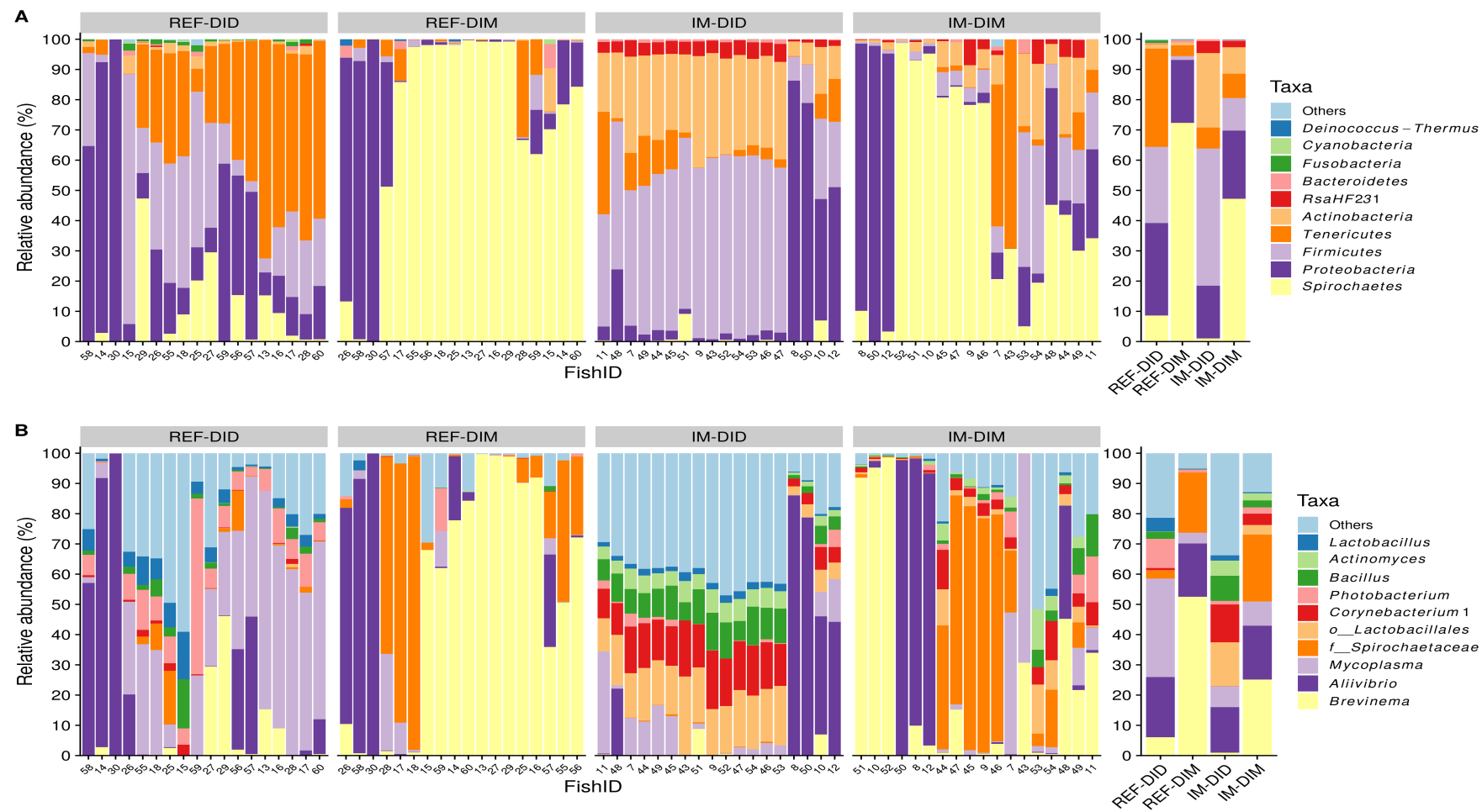

Fig. 1. Top 10 most abundant taxa of all samples at phylum (A) and genus (B) level. The samples are grouped by sample origins and dietary treatments. The mean

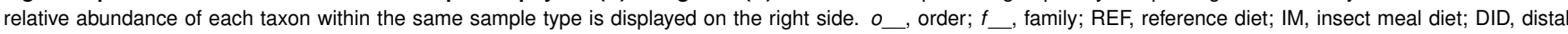
intestine digesta; DIM, distal intestine mucosa.

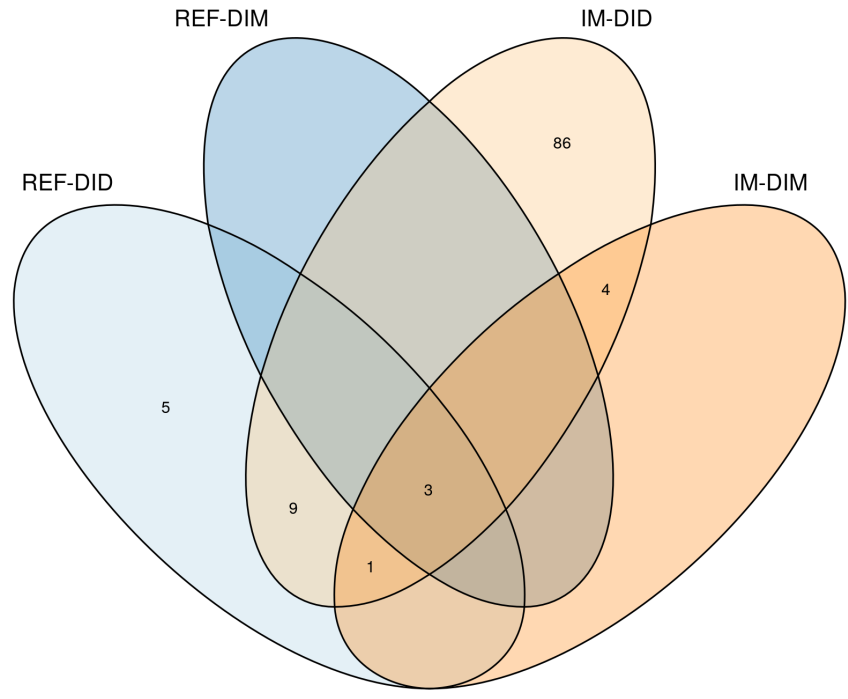

Fig. 2. Venn's diagram showing the shared and unique core microbiota in each sample type. The core microbiota was computed using a prevalence threshold of $80 \%$. REF, reference diet; IM, insect meal diet; DID, distal intestine digesta; DIM, distal intestine mucosa.

$(p<0.05)$ (Fig. 3). Independent of sample origin, all the alpha-diversity indices were higher in fish fed the IM diet than those fed the REF diet $(p<0.05)$. A significant interaction between the diet and sample origin effect was detected for the observed species $(p=0.031)$ and Faith's phylogenetic diversity $(p=0.002)$, both of which showed a stronger diet effect in digesta samples than mucosa samples.

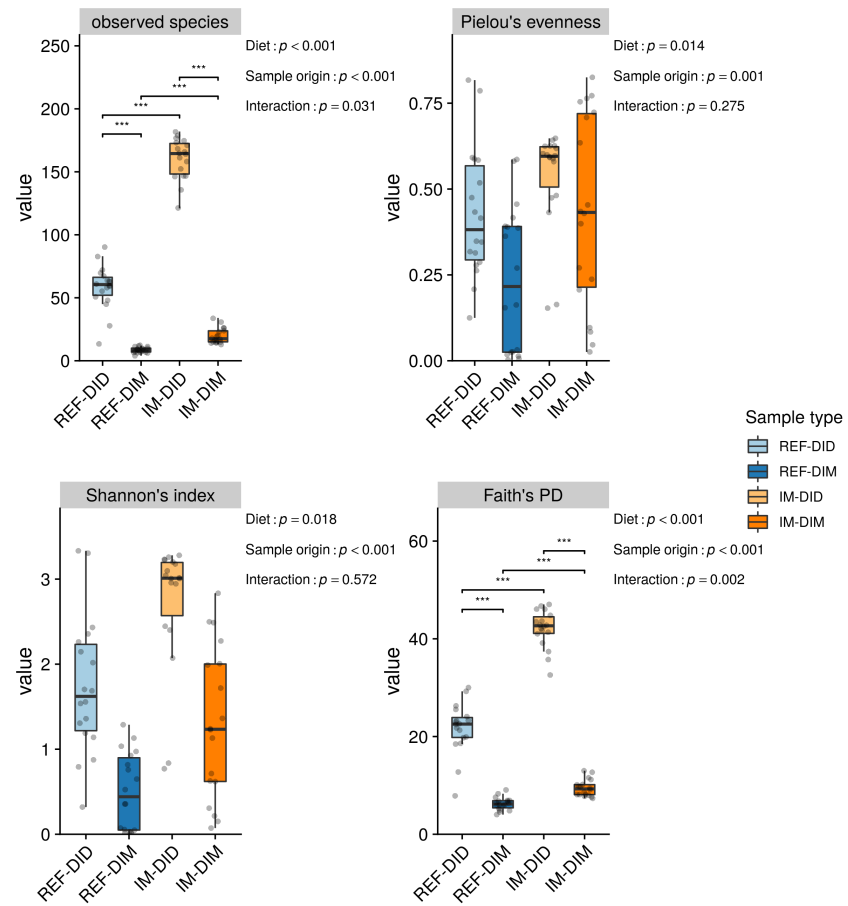

Fig. 3. The sample origin and diet effects on the alpha-diversity of distal intestinal microbiota in seawater phase Atlantic salmon. The $p$ value of the main effects and their interaction are displayed on the top-right corner of each sub-plot. Asterisks denote statistically significant differences $\left({ }^{*}, p<0.05 ;{ }^{* *}, p<0.01 ;{ }^{* * *}, p\right.$ $<0.001)$. PD, phylogenetic diversity; REF, reference diet; IM, insect meal diet; DID, distal intestine digesta; DIM, distal intestine mucosa. 
Beta-diversity. The PCoA plots built on the Jaccard and unweighted UniFrac distance matrix showed clear separations of samples belonging to different dietary groups and sample origins (Fig. 4A-B). However, the average distance between samples from different dietary groups was dependent on sample origin. Specifically, mucosa samples from different dietary groups formed clusters close to each other, whereas digesta samples from different dietary groups were far apart. The PCoA plots built on the Aitchison and PHILR transformed Euclidean distance matrix also showed separations of samples belonging to different dietary groups and sample origins (Fig. 4C-D). Again, the average distance between samples from different dietary groups was dependent on sample origin. Mucosa samples from different dietary groups formed clusters boarding (Fig. 4C) or overlapping (Fig. 4D) each other, whereas digesta samples from different dietary groups were more clearly separated.

The PERMANOVA and its following conditional contrasts largely confirmed the PCoA results. Regardless of the distance matrix used, both main factors had significant effects on the beta-diversity and their interaction was significant as well $(p<0.05)$ (Table 1). Results on the tests of homogeneity of multivariate dispersions are shown in Table 2. For Jaccard distance, significant differences in the multivariate dispersions were observed between digesta and mucosa samples for both diets (REF-DID VS. REF-DIM, $p=0.045$; IM-DID VS. IM-DIM, $p=0.002$ ), and between diets for digesta samples (REF-DID VS. IM-DID, $p=0.002$ ). For unweighted UniFrac distance, IM-DID showed lower multivariate dispersions than other sample types resulting in significant differences compared to REF-DID ( $p=0.002)$ and IM-DIM ( $p$ $=0.002$ ). For Aitchison distance, REF-DIM showed lower multivariate dispersions than other sample types resulting in significant differences compared to REF-DID $(p=0.046)$ and IM-DIM $(p=0.046)$. For PHILR transformed Euclidean distance, the differences in the multivariate dispersions among the sample types were not significant $(p>0.05)$.

\section{Significant associations between microbial clades and} sample metadata. The multivariate association analysis identified 53 taxa showing significant associations with the metadata of interest (Fig. 5A). The diagnostic plots showing the raw data underlying the significant associations are shown in Fig. S3-8. Forty-seven differentially abundant taxa were identified for the sample origin effect, 45 of which, including Bacillus, Enterococcus, Flavobacterium, Lactobacillus, Lactococcus, Leuconostoc, Mycoplasma, Peptostreptococcus, Photobacterium, Staphylococcus, Streptococcus, Vagococcus and Weissella, showed lower relative abundances in the mucosa than the digesta (Fig. S3). In contrast, two taxa belonging to the Spirochaetes phylum, B. andersonii and unclassified Spirochaetaceae, were enriched in the mucosa (Fig. 5B). Thirty-six differentially abundant taxa were identified for the diet effect, 26 of which showed increased relative abundances in fish fed the IM diet (Fig. S4). Among these 26 taxa, some were enriched in both intestinal digesta and mucosa which included Actinomyces, unclassified Bacillaceae, Bacillus, unclassified Beutenbergiaceae, Brevibac- terium, Corynebacterium 1, Enterococcus, unclassified Lactobacillales, Microbacterium, Oceanobacillus and unclassified RsaHF231 (partially illustrated as Fig. 5C). For the histological scores, the relative abundance of unclassified Sphingobacteriaceae and unclassified RsaHF231 were found to increase and decrease, respectively, in fish scored abnormal regarding lamina propria cellularity (lpc) in distal intestine (Fig. S5). The relative abundance of Acinetobacter and Pseudomonas were negatively correlated with the distal intestine somatic index (DISI) (Fig. S6). Six taxa, including Actinomyces, B. andersonii, Kurthia, Lysobacter, Microbacterium and the unclassified Sphingobacteriaceae, were found to associate with the expression of genes related to immune responses (Fig. S7). Notably, the relative abundance of B. andersonii showed a clear positive correlation with the expression levels of immune genes (Fig. 5D), which decreased as the PC1 of the PCA increased. Furthermore, 3 taxa including Cellulosimicrobium, Glutamicibacter and the unclassified Spirochaetaceae were found to associate with the expression of genes related to barrier functions (Fig. S8). The relative abundance of the unclassified Spirochaetaceae showed a negative correlation with the expression levels of barrier function relevant genes (Fig. 5E), which decreased as the PC1 of the PCA increased.

\section{Discussion}

Core microbiota. In accordance with previous studies in Atlantic salmon (20,33-38), Aliivibrio, B. andersonii and Mycoplasma were identified as core microbiota in the present study. Aliivibrio is commonly found in the seawater phase Atlantic salmon intestine (35-37, 39-43) and has been identified as a core taxon of both wild and captive Atlantic salmon $(34,36,37)$. Provided its common presence in seawater, Aliivibrio may have originated from the surrounding water and colonized the intestinal mucosa as Atlantic salmon constantly drink seawater to prevent dehydration in a hyperosmotic environment. Currently, the taxon Aliivibrio comprises of four closely related species including Aliivibrio fischeri, Aliivibrio logei, Aliivibrio salmonicida and Aliivibrio wodanis, which were split from the Vibrio genus and reclassified as Aliivibrio in 2007 (44). Strains of A. fischeri and A. logei have been described as bioluminescent symbionts of certain fishes and squids (45), whereas A. salmonicida and A. wodanis have been identified as pathogens for Atlantic salmon causing cold-water vibriosis (46) and 'winter ulcer' (47), respectively.

Though Spirochaetes has typically been found in low abundances in the Atlantic salmon intestine (19, 23, 27, 39), two recent studies have identified $B$. andersonii as a core taxon of both digesta- and mucosa-associated intestinal microbiota in seawater phase Atlantic salmon $(35,36)$. Furthermore, $B$. andersonii is also a predominant taxon in the digesta and mucosa in one of the studies (36). B. andersonii was initially isolated from short-tailed shrews (Blarina brevicauda) and white-footed mice (Peromyscus leucopus) as an infectious pathogen (48). This taxon has also been found in the intestine and gill tissue of rainbow trout (Oncorhynchus 

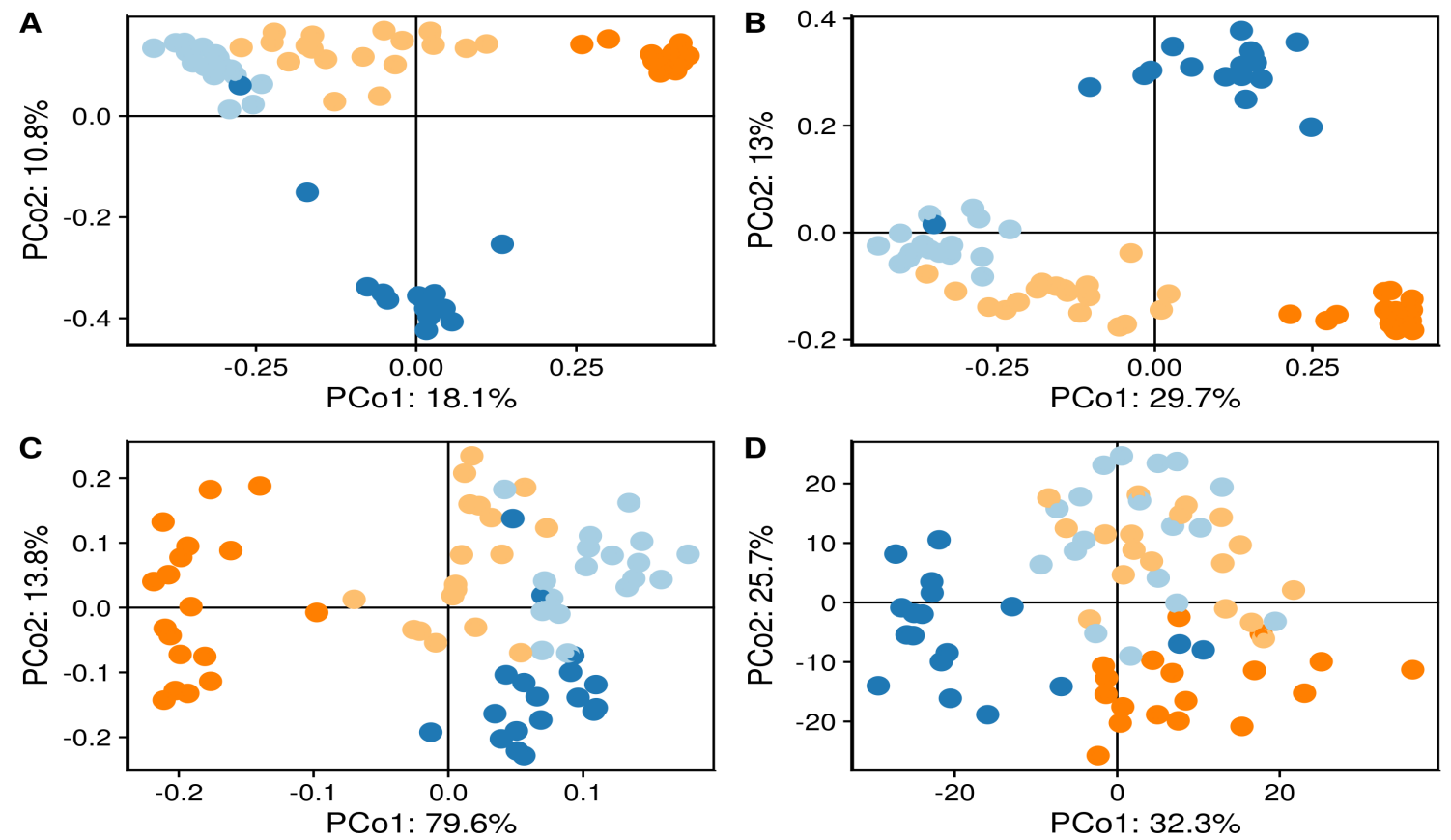

Sample type

- REF-DID

REF-DIM

IM-DID

IM-DIM

Fig. 4. The sample origin and diet effects on the beta-diversity of distal intestinal microbiota in seawater phase Atlantic salmon. The PCoA plots were built on Jaccard (A), unweighted UniFrac (B), Aitchison (C) and phylogenetic isometric log-ratio (PHILR) transformed Euclidean (D) distance matrix, respectively. PCo, principle coordinate; REF, reference diet; IM, insect meal diet; DID, distal intestine digesta; DIM, distal intestine mucosa.

Table 1. PERMANOVA results and subsequent conditional contrasts.

\begin{tabular}{|c|c|c|c|c|c|c|c|}
\hline \multirow[b]{2}{*}{ Distance matrix } & \multicolumn{2}{|c|}{ Main effects } & \multirow[b]{2}{*}{ Interaction } & \multicolumn{4}{|c|}{ Conditional contrasts } \\
\hline & Diet & $\begin{array}{l}\text { Sample } \\
\text { origin }\end{array}$ & & $\begin{array}{l}\text { REF-DIC } \\
\text { VS. } \\
\text { IM-DIC }\end{array}$ & $\begin{array}{l}\text { REF-DIM } \\
\text { VS. } \\
\text { IM-DIM }\end{array}$ & $\begin{array}{l}\text { REF-DIC } \\
\text { VS. } \\
\text { REF-DIM }\end{array}$ & $\begin{array}{l}\text { IM-DIC } \\
\text { VS. } \\
\text { IM-DIM }\end{array}$ \\
\hline Jaccard & 0.001 & 0.001 & 0.001 & 0.001 & 0.001 & 0.001 & 0.001 \\
\hline Unweighted UniFrac & $0.001^{1}$ & 0.001 & 0.001 & $0.001^{1}$ & 0.001 & 0.001 & 0.001 \\
\hline Aitchison & 0.001 & 0.003 & 0.004 & 0.002 & 0.004 & $0.004^{1}$ & $0.002^{1}$ \\
\hline PHILR (Euclidean) ${ }^{2}$ & 0.001 & 0.001 & 0.001 & 0.001 & 0.005 & 0.001 & 0.001 \\
\hline
\end{tabular}

Abbreviations: REF, reference diet; IM, insect meal diet; DID, distal intestine digesta; DIM, distal intestine mucosa.

${ }^{1}$ Monte Carlo $p$ value

${ }^{2}$ Phylogenetic isometric log-ratio transformed Euclidean distance.

Table 2. Test of homogeneity of multivariate dispersions among groups.

\begin{tabular}{lllll}
\hline & \multicolumn{4}{c}{ Conditional contrasts } \\
\cline { 2 - 5 } Distance matrix & REF-DID & REF-DIM & REF-DID & IM-DID \\
& VS. & VS. & VS. & VS. \\
& IM-DID & IM-DIM & REF-DIM & IM-DIM \\
\hline Jaccard & 0.002 & 0.103 & 0.015 & 0.002 \\
Unweighted UniFrac & 0.008 & 0.662 & 0.151 & 0.012 \\
Aitchison & 0.453 & 0.046 & 0.046 & 0.369 \\
PHILR (Euclidean) $^{1}$ & 0.240 & 0.266 & 0.240 & 0.266 \\
\hline
\end{tabular}

Abbreviations: REF, reference diet; IM, insect meal diet; DID, distal intestine digesta; DIM, distal intestine mucosa.

${ }^{1}$ Phylogenetic isometric log-ratio transformed Euclidean distance.

mykiss) (49), and intestinal digesta of Senegalese sole (Solea senegalensis)(50).

Mycoplasma is widely distributed in nature and well known for its minute size and lack of cell wall. Like Aliivibrio, Mycoplasma has been frequently identified as a core taxon of both wild and captive Atlantic salmon as well $(20,33,35-38)$. It was found to be more abundant in marine adults than in freshwater juvenile Atlantic salmon (37) and sporadically predominate intestinal microbial community in the digesta $(20,36,37,41,51)$ and mucosa $(35)$ reaching as high as $>90 \%$ of total read counts in extreme cases. Due to its small compact genome and limited biosynthesis capacities, Mycoplasma typically forms obligate parasitic or commensal relationships with its host to obtain necessary nutrients such as amino acids, fatty acids and sterols (52). The major acids produced by Mycoplasma during fermentation are lactic acid and acetic acid (53), the latter of which was found in 
bioRxiv preprint doi: https://doi.org/10.1101/2020.05.08.083899; this version posted May 24, 2020. The copyright holder for this preprint (which was not certified by peer review) is the author/funder, who has granted bioRxiv a license to display the preprint in perpetuity. It is made available under aCC-BY-ND 4.0 International license.


Fig. 5. Significant associations between microbial clades and sample metadata. (A) Heatmap summarizing all the significant associations between microbial clades and sample metadata. Color key: $-\log \left(q\right.$-value) ${ }^{*} \operatorname{sign}($ coefficient). Cells that denote significant associations are colored (red or blue) and overlaid with a plus (+) or minus (-) sign that indicates the direction of association: Diet (+), higher abundance in salmon fed the IM diet; Sample_origin (+), higher abundance in mucosa samples; Histology_lpc (+), higher abundance in salmon scored abnormal regarding lamina propria cellularity (Ipc) in the distal intestine; DISI (+), positive correlation between microbial clade abundance and distal intestine somatic index (DISI); qPCR_immune_response (+) / qPCR_barrier_function (+), negative correlation between microbial clade abundance and the gene expression levels. (B) Taxa that are more abundant in the intestinal mucosa than the digesta. (C) Representative taxa showing increased relative abundances in both intestinal digesta and mucosa of salmon fed the IM diet. (D) The positive correlation between the relative abundance of $B$. andersonii and immune gene expression levels in the distal intestine. Note that the expression levels of the immune genes decreased as the PC1 of the PCA increased. (E) The negative correlation between the relative abundance of the unclassified Spirochaetaceae and the expression levels of barrier function relevant genes. Also note that the expression levels of the barrier function relevant genes

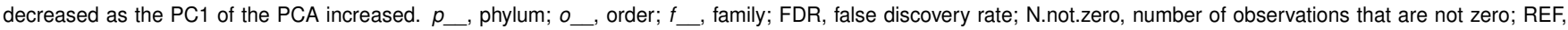
reference diet; IM, insect meal diet.

our recent studies to be 2-4 orders of magnitude higher than other short-chain fatty acids in the Atlantic salmon distal intestine (unpublished data). A recent study found that Atlantic salmon Mycoplasma, recovered by shotgun metagenomic sequencing, was closely related to Mycoplasma penetrans and Mycoplasma yeatsii (20). Compared to these closely related Mycoplasma species, the salmon Mycoplasma appears to carry a much lower number of unique genes that are enriched in carbohydrate uptake and low in peptidase synthesis.

Sample origin effect. In line with previous findings in mammals and fish $(19,22-25)$, we observed substantial differences between digesta- and mucosa-associated microbiota. The microbial richness and diversity were much higher 
in the digesta than the mucosa, as previously observed in seawater phase Atlantic salmon (19, 23, 26). Furthermore, most of the bacterial taxa in the distal intestine, including those commonly found in the Atlantic salmon intestine such as Bacillus, Enterococcus, Flavobacterium, Lactobacillus, Lactococcus, Leuconostoc, Mycoplasma, Peptostreptococcus, Photobacterium, Staphylococcus, Streptococcus, Vagococcus and Weissella, were less abundant in the mucosa than in the digesta. These results are suggestive of a selection pressure from the host that determines which microbial clades colonize and flourish in the intestinal mucus layer (54). In this study, two taxa belonging to the Spirochaetes phylum, B. andersonii and unclassified Spirochaetaceae, were more abundant in the distal intestine mucosa than the digesta. As aforementioned, Spirochaetes were typically found in low abundances in the Atlantic salmon intestine. Yet a recent study also showed that irrespective of diets $B$. andersonii seemed to be more abundant in the intestinal mucosa than the digesta of seawater phase Atlantic salmon (36). Known for high motility and chemotactic attraction to mucin, some Spirochaetes can penetrate the mucus and associate with the intestinal mucosa (55-57). Further work is required to confirm whether these taxa are consistently enriched in the intestinal mucus layer of seawater phase Atlantic salmon.

Diet effect. Diet is one of the key factors in shaping the fish intestinal microbiota. In agreement with previous findings in rainbow trout $(29,58,59)$ and laying hens $(60,61)$, we found that the insect meal diet altered the distal intestinal microbiota assemblage resulting in higher microbial richness and diversity. Our findings, showing that the insect meal diet increased the relative abundance of Actinomyces, Bacillus, Brevibacterium, Corynebacterium 1 and Enterococcus, are in accord with recent studies in rainbow trout fed diets containing $30 \%$ black soldier fly larvae meal $(29,59)$. Importantly, these results were partly confirmed in other studies employing fluorescence in situ hybridization for targeted profiling of changes in the intestinal microbiota. Specifically, increased absolute abundance of Lactobacillus/Enterococcus was found in rainbow trout fed $20 \%$ dietary black soldier fly larvae meal (62), whereas increased absolute abundance of Bacillus, Enterococcus and Lactobacillus was documented in Siberian sturgeon (Acipenser baerii) fed 15\% black soldier fly larvae meal (63).

The increases in the relative abundance of specific microbial clades in Atlantic salmon fed the insect meal diet may be explained by feed-borne microbiota and/or feed composition. Bacterial taxa, including Actinomyces, Bacillus, Brevibacterium, Corynebacterium, Enterococcus, Oceanobacillus and RsaHF231, have been found in black soldier fly whole larvae or larvae intestine (64-67). The fact that RsaHF231 has not been documented in fish before indicates that these bacterial taxa may have partially originated from black soldier fly larvae meal. Our results from the freshwater feeding trial showed that these bacterial taxa were also enriched in the intestinal digesta and mucosa of Atlantic salmon smolts fed an insect meal diet containing 60\% soldier fly larvae meal. Importantly, these bacterial taxa were also detected in the feed pellets which contained considerable amount of bacterial DNA that is comparable to intestinal digesta (unpublished data). Given the hydrothermal treatments the feed pellets underwent during the extrusion, the feed-borne microbiota profiled by the DNA sequencing techniques could have largely originated from dead bacteria and bacterial spores rather than living bacteria. As sequencing-based methods cannot differentiate between living and dead cells, future studies should investigate to what extent the feed-borne microbiota may contribute to, or confound the observed diet effects on intestinal microbiota, using methods that distinguish living and dead bacteria such as viability PCR and RNA sequencing (68). On the other hand, unique nutrients in the insect meal diet such as chitin, an essential component of the insect exoskeleton, may have selectively promoted the growth of certain intestinal microbes. Actinomyces species are often identified as active chitin degraders showing enhanced growth and activity upon chitin addition (69). Many bacterial species belonging to Bacillus can produce chitinase (70). Bacillus and Lactobacillus were two of the predominant taxa in the intestinal mucosa of Atlantic salmon fed a $5 \%$ chitin diet, the former of which displayed the highest in vitro chitinase activity (71).

\section{Significant interactions between diet and sample ori-} gin effect. We observed in the present study that the diet effect on the intestinal microbial community richness and structure was dependent on the sample origin, with mucosaassociated intestinal microbiota showing higher resilience to the dietary change. Our results corroborate previous findings in rainbow trout revealing that mucosa-associated intestinal microbiota was less influenced by dietary inclusion of $30 \%$ black soldier fly larvae meal compared to digesta-associated intestinal microbiota $(28,29)$. Results from molecular-based studies on salmonid intestinal microbiota hitherto suggest that diet modulates digesta- and mucosa-associated intestinal microbiota to varying degrees with the latter generally being more resilient to dietary interventions $(19,26-29,35)$. As such, current practices of profiling only one of or a mixture of digesta- and mucosa-associated microbiota may obscure the response of intestinal microbiota to dietary changes. To fully unveil the response of intestinal microbiota to dietary changes, we recommend concurrent profiling of digesta- and mucosa-associated intestinal microbiota whenever it is feasible.

\section{Significant associations between microbial clades and} sample metadata. To our knowledge, only a few studies have carried out association analysis between intestinal microbial clades and host responses in Atlantic salmon. As such, our results should be treated as preliminary observations and critically evaluated in later studies. Herein, we highlight the significant associations between two mucosaenriched taxa and host gene expressions in the intestine. Specifically, B. andersonii, part of the core microbiota, was associated with the expression of genes related to proand anti-inflammatory responses whereas the unclassified Spirochaetaceae was associated with the expression of genes 
related to barrier function. Intestinal microbiota is well known to modulate the local immune responses and intestinal epithelial barrier function (72). Furthermore, it is hypothesized that mucosa-associated microbiota plays a more crucial role in shaping the host immunity in that it can interact both directly and indirectly with intestinal epithelial barrier whereas digesta-associated microbiota can only interact indirectly (54). Taken together, further research should be undertaken to investigate the potential ecological and functional significance of these two taxa for seawater phase Atlantic salmon.

\section{Quality control: use of mock and negative controls.} As in any field of research, conducting a well-controlled microbiome study requires great care in the experiment design such as setting up appropriate experimental controls. The use of mock as a positive control allows for critical evaluation and optimization of microbiota profiling workflow. That all the bacterial taxa in the mock were correctly identified at the genus level indicates that the current workflow is reliable for the taxonomic profiling of intestinal microbiota. Furthermore, the taxonomic profile of mock from different DNA extraction batches was fairly similar, suggesting that the results generated by the current workflow are also largely reproducible. However, the low concordance between the expected and observed relative abundance of bacterial taxa in the mock is reminiscent of the fact that bias is introduced at different steps of the marker-gene survey (73-75), among which DNA extraction and PCR amplification are the two largest sources of bias due to preferential extraction and amplification of some microbial clades over others. In line with previous observations that Gram-positive bacteria may be more subjective to incomplete lysis during DNA extraction due to their tough cell walls $(76,77)$, the recovery of most Grampositive bacteria in the mock was lower than the expected. The insufficient lysing of Gram-positive bacteria in the mock was largely mitigated in our later experiments by using a mixture of beads with different sizes for the bead beating during DNA extraction (unpublished data). The bias in the markergene sequencing experiments, as reflected in the observed taxonomic profile of the mock, highlights the necessity of validating such results by absolute quantification techniques such as cultivation (if possible), qPCR, flow cytometry and fluorescence in situ hybridization.

Reagent contamination is a common issue in molecularbased studies of microbial communities. The main contaminating taxon identified in this study is Pseudomonas, which has been reported as a common reagent contaminant in numerous studies (78-84). Given the dominance of Pseudomonas in the negative controls of both DNA extraction and PCR, most of the observed contamination has likely derived from PCR reagents such as molecular-grade water (85-87). Notably, Pseudomonas has also been isolated from intestinal digesta and mucosa of Atlantic salmon by traditional culturing approaches $(71,88-90)$, and reported as a member of Atlantic salmon core microbiota in culture-independent studies $(19,23,33,34,38,91)$. Due to the low taxonomic resolution of amplicon sequencing, it is difficult to discern contaminat- ing taxa from true signals solely based on taxonomic labels. The inclusion of negative controls, coupled with quantifications of microbial DNA concentration in the samples, has enabled fast and reliable identification of contaminating taxa in this study. Besides Pseudomonas, other common reagent contaminants, including Bradyrhizobium, Burkholderia, Comamonas, Methylobacterium, Propionibacterium, Ralstonia, Sphingomonas and Stenotrophomonas (83, 85, 87, 92-96), have also been frequently reported as members of Atlantic salmon intestinal microbiota, indicating that existing studies of Atlantic salmon intestinal microbiota may have been plagued with reagent contamination that is hard to ascertain due to lack of negative controls. As reagent contamination is unavoidable, study-specific and can critically influence sequencing-based microbiome analyses $(85,97,98)$, negative controls should always be included and sequenced in microbiome studies especially when dealing with low microbial biomass samples like intestinal mucosa.

Conclusion. In summary, we confirmed previous findings in mammals and fish that intestinal digesta and mucosa harbor microbial communities with clear differences. Regardless of diet, microbial richness and diversity were much higher in the digesta than the mucosa. The insect meal diet altered the distal intestinal microbiota assemblage resulting in higher microbial richness and diversity. The diet effect was however dependent on the sample origin, with mucosa-associated intestinal microbiota being more resilient to the dietary change. To fully unveil the response of intestinal microbiota to dietary changes, concurrent profiling of digesta- and mucosa-associated intestinal microbiota is recommended whenever feasible. Lastly, we identified two mucosa-enriched taxa, Brevinema andersonii and unclassified Spirochaetaceae, which seemed to be associated with the expression in the distal intestine of genes related to immune responses and barrier function, respectively. As mucosaassociated microbiota could play a more critical role in shaping the host metabolism, their potential functional significance for seawater phase Atlantic salmon merits further investigations.

\section{Materials and Methods}

Experimental fish, diet and sampling. A 16-week seawater feeding trial with Atlantic salmon (initial body weight $=$ $1.40 \mathrm{~kg}$, S.D. $=0.043 \mathrm{~kg}$ ) was conducted at the Gildeskål Research Station (GIFAS), Nordland, Norway, in accordance with laws regulating the experimentation with live animals in Norway. The experimental fish were randomly assigned into 6 net pens $(5 \times 5 \times 5 \mathrm{~m})$ each containing 90 fish. The fish were fed, in triplicate net pens, either a commercially-relevant reference diet (REF) with a combination of fish meal, soy protein concentrate, pea protein concentrate, corn gluten and wheat gluten as the protein source, or an insect meal diet (IM) wherein all the fish meal and most of the pea protein concentrate were replaced by black soldier fly larvae meal. Fish were fed by hand until apparent satiation once or twice daily depending on the duration of daylight. During the feed- 
ing trial, the water temperature ranged from $7{ }^{\circ} \mathrm{C}$ to $13{ }^{\circ} \mathrm{C}$. Further details on the formulation and chemical composition of the diets, and insect meal have been reported elsewhere $(31,32)$.

At the termination of the feeding trial, 6 fish were randomly taken from each net pen, anesthetized with tricaine methanesulfonate (MS222 ${ }^{\circledR}$; Argent Chemical Laboratories, Redmond, WA, USA) and euthanized by a sharp blow to the head. After cleaning the exterior of each fish with $70 \%$ ethanol, the distal intestine, i.e., the segment from the increase in intestinal diameter and the appearance of transverse luminal folds to the anus, was aseptically removed from the abdominal cavity, placed in a sterile Petri dish and opened longitudinally. Only fish with digesta along the whole intestine were sampled to ensure that the intestine had been exposed to the diets. The intestinal digesta was collected into a $50 \mathrm{~mL}$ skirted sterile centrifuge tube and mixed thoroughly using a spatula. An aliquot of the homogenate was then transferred into a $1.5 \mathrm{~mL}$ sterile Eppendorf tube and snap-frozen in liquid $\mathrm{N}_{2}$ for the profiling of digesta-associated intestinal microbiota. A tissue section from the mid part of the distal intestine was excised and rinsed in sterile phosphatebuffered saline 3 times to remove traces of the remaining digesta. After rinsing, the intestinal tissue was longitudinally cut into 3 pieces for histological evaluation (fixed in $4 \%$ phosphate-buffered formaldehyde solution for $24 \mathrm{~h}$ and transferred to $70 \%$ ethanol for storage), RNA extraction (preserved in RNAlater solution and stored at $-20{ }^{\circ} \mathrm{C}$ ) and profiling of mucosa-associated intestinal microbiota (snap-frozen in liquid $\mathrm{N}_{2}$ ), respectively. The collection of microbiota samples was performed near a gas burner to secure aseptic conditions. After the sampling of each fish, tools were cleaned and decontaminated by a $70 \%$ ethanol spray and flaming. Microbiota samples of the distal intestine digesta (DID) and mucosa (DIM) were transported in dry ice and stored at $-80^{\circ} \mathrm{C}$ until DNA extraction.

DNA extraction. Total DNA was extracted from $\sim 200 \mathrm{mg}$ distal intestine digesta or mucosa using the QIAamp ${ }^{\circledR}$ DNA Stool Mini Kit (Qiagen, Hilden, Germany; catalog no., 51504) with some modifications to the manufacturer's specifications as described before (19), except that $2 \mathrm{~mL}$ prefilled bead tubes (Qiagen; catalog no., 13118-50) were used for the bead beating. For quality control purposes, a companion "blank extraction" sample was added to each batch of sample DNA extraction by omitting the input material, whereas an additional microbial community standard (ZymoBIOMICS $^{\mathrm{TM}}$, Zymo Research, California, USA; catalog no., D6300), i.e. mock, was included for each DNA extraction kit as a positive control. The mock consists of 8 bacteria (Pseudomonas aeruginosa, Escherichia coli, Salmonella enterica, Lactobacillus fermentum, Enterococcus faecalis, Staphylococcus aureus, Listeria monocytogenes, Bacillus subtilis) and 2 yeasts (Saccharomyces cerevisiae, Cryptococcus neoformans).

Amplicon PCR. The V1-2 hypervariable regions of the bacterial 16S rRNA gene were amplified using the primer set 27F
(5'-AGA GTT TGA TCM TGG CTC AG-3') and 338R (5'GCW GCC WCC CGT AGG WGT-3') (99). The PCR was run in a total reaction volume of $25 \mu \mathrm{L}$ containing $12.5 \mu \mathrm{L}$ of Phusion ${ }^{\circledR}$ High-Fidelity PCR Master Mix (Thermo Scientific, CA, USA; catalog no., F531L), $10.9 \mu \mathrm{L}$ molecular grade $\mathrm{H}_{2} \mathrm{O}, 1 \mu \mathrm{L}$ DNA template and $0.3 \mu \mathrm{L}$ of each primer $(10 \mu \mathrm{M})$. The amplification program was set as follows: initial denaturation at $98{ }^{\circ} \mathrm{C}$ for $3 \mathrm{~min} ; 35$ cycles of denaturation at 98 ${ }^{\circ} \mathrm{C}$ for $15 \mathrm{~s}$, annealing decreasing from $63{ }^{\circ} \mathrm{C}$ to $53{ }^{\circ} \mathrm{C}$ in 10 cycles for $30 \mathrm{~s}$ followed by 25 cycles at $53{ }^{\circ} \mathrm{C}$ for $30 \mathrm{~s}$, and extension at $72{ }^{\circ} \mathrm{C}$ for $30 \mathrm{~s}$; followed by a final extension at $72{ }^{\circ} \mathrm{C}$ for $10 \mathrm{~min}$. For samples with faint or invisible bands in the agarose gel after PCR, the PCR condition was optimized by applying serial dilutions to the DNA templates to reduce the influence of PCR inhibitors. All the digesta samples were diluted 1:2 in buffer ATE (10 mM Tris-Cl, $\mathrm{pH} 8.3$, with 0.1 $\mathrm{mM}$ EDTA and $0.04 \% \mathrm{NaN}_{3}$ ) whereas all the mucosa samples were diluted 1:32. The formal amplicon PCR was run in duplicate incorporating two negative PCR controls, which were generated by replacing the template DNA with molecular grade $\mathrm{H}_{2} \mathrm{O}$. The duplicate $\mathrm{PCR}$ products were then pooled and examined by a $1.5 \%$ agarose gel electrophoresis.

Quantification of 16S rRNA gene by qPCR. To assist in identifying contaminating sequences, the 16S rRNA gene quantity in the diluted DNA templates used for the amplicon PCR was measured by qPCR. The qPCR assays were performed using a universal primer set (forward, 5'-CCA TGA AGT CGG AAT CGC TAG-3'; reverse, 5'-GCT TGA CGG GCG GTG T-3') that has been used for bacterial DNA quantification in previous studies $(100,101)$. The assays were carried out using the LightCycler 96 (Roche Applied Science, Basel, Switzerland) in a $10 \mu \mathrm{L}$ reaction volume, which contained $2 \mu \mathrm{L}$ of PCR-grade $\mathrm{H}_{2} \mathrm{O}, 1 \mu \mathrm{L}$ diluted DNA template, $5 \mu \mathrm{L}$ LightCycler 480 SYBR Green I Master Mix (Roche Applied Science) and $1 \mu \mathrm{L}(3 \mu \mathrm{M})$ of each primer. Samples, together with the extraction blanks and mock, were run in duplicate in addition to Femto ${ }^{\mathrm{TM}}$ bacterial DNA standards (Zymo Research; catalog no., E2006) and a no-template control of the qPCR assay. The qPCR program encompassed an initial enzyme activation step at $95^{\circ} \mathrm{C}$ for $2 \mathrm{~min}, 45$ threestep cycles of $95{ }^{\circ} \mathrm{C}$ for $10 \mathrm{~s}, 60^{\circ} \mathrm{C}$ for $30 \mathrm{~s}$ and $72{ }^{\circ} \mathrm{C}$ for $15 \mathrm{~s}$, and a melting curve analysis at the end. Quantification cycle $(\mathrm{Cq})$ values were determined using the second derivative method (102). The specificity of qPCR amplification was confirmed by evaluating the melting curve of qPCR products and the band pattern on the agarose gel after electrophoresis. The inter-plate calibration factor was calculated following the method described in (103), using the bacterial DNA standards as inter-plate calibrators.

Sequencing. The sequencing was carried out on a Miseq platform following the Illumina 16S metagenomic sequencing library preparation protocol (104). Briefly, the PCR products were cleaned using the Agencourt AMPure XP system (Beckman Coulter, Indiana, USA; catalog no., A63881), multiplexed by dual indexing using the Nextera XT Index Kit (Illumina, California, USA; catalog no., FC-131-1096) 
and purified again using the AMPure beads. After the second clean-up, representative libraries were selected and analyzed using the Agilent DNA 1000 Kit (Agilent Technologies, California, USA; catalog no., 5067-1505) to verify the library size. Cleaned libraries were quantified using the Invitrogen Qubit ${ }^{\mathrm{TM}}$ dsDNA HS Assay Kit (Thermo Fisher Scientific, California, USA; catalog no., Q32854), diluted to 4 $\mathrm{nM}$ in $10 \mathrm{mM}$ Tris (pH 8.5) and finally pooled in an equal volume. Negative controls with library concentrations lower than $4 \mathrm{nM}$ were pooled in equal volume directly. Due to the low diversity of amplicon library, 15\% Illumina generated PhiX control (catalog no., FC-110-3001) was spiked in by combining $510 \mu \mathrm{L}$ amplicon library with $90 \mu \mathrm{L}$ PhiX control library. The library was loaded at $6 \mathrm{pM}$ and sequenced using the Miseq Reagent Kit v3 (600-cycle) (Illumina; catalog no., MS-102-3003).

Sequence data processing. The raw sequence data were processed by the DADA2 1.14 in R 3.6.3 (105) to infer amplicon sequence variants (ASVs) (106). Specifically, the demultiplexed paired-ended reads were trimmed off the primer sequences (forward reads, first $20 \mathrm{bps}$; reverse reads, first $18 \mathrm{bps}$ ), truncated at the position where the median Phred quality score crashed (forward reads, at position $290 \mathrm{bp}$; reverse reads, at position $248 \mathrm{bp}$ ) and filtered off low-quality reads. After trimming and filtering, the run-specific error rates were estimated and the ASVs were inferred by pooling reads from all the samples sequenced in the same run. The chimeras were removed using the "pooled" method after merging the reads. The resulting raw ASV table and representative sequences were imported into QIIME2 (version, 2020.2) (107). The taxonomy was assigned by a scikitlearn naive Bayes machine-learning classifier (108), which was trained on the SILVA $13299 \%$ OTUs (109) that were trimmed to only include the regions of 16S rRNA gene amplified by our primers. Taxa identified as chloroplasts or mitochondria were excluded from the ASV table. The ASV table was conservatively filtered to remove ASVs that had no phylum-level taxonomic assignment or appeared in only one biological sample. Contaminating ASVs were identified based on two suggested criteria: contaminants are often found in negative controls and inversely correlate with sample DNA concentration (84). The ASVs filtered from the raw ASV table were also removed from the representative sequences, which were then inserted into a reference phylogenetic tree built on the SILVA 128 database using SEPP (110). The alpha rarefaction curves and the core metrics results were generated with a sampling depth of 10000 and 2047 sequences per sample, respectively. For downstream data analysis and visualization, QIIME2 artifacts were imported into $\mathrm{R}$ using the qiime2R package (111) and a phyloseq (112) object was assembled from the sample metadata, ASV table, taxonomy and phylogenetic tree. The core microbiota and alpha-diversity indices were computed using the ASV table collapsed at the species level. The core microbiota was calculated based on the $80 \%$ prevalence threshold and visualized by the Venn's diagram. The alpha-diversity indices, including observed species, Pielou's evenness, Shannon's in- dex and Faith's phylogenetic diversity (PD), were computed via the R packages microbiome (113) and picante (114). For beta-diversity analyses, we used distance matrices including Jaccard distance, unweighted UniFrac distance, Aitchison distance and phylogenetic isometric log-ratio (PHILR) transformed Euclidean distance. Since rarefying remains to be the best solution for unweighted distance matrices (115), the Jaccard distance and unweighted UniFrac distance were computed in QIIME2 using the rarefied ASV table. The compositionality-aware distance matrices, Aitchison distance and PHILR transformed Euclidean distance, were calculated using the unrarefied ASV table. The Aitchison distance was computed by the DEICODE plugin in QIIME2, a form of Aitchison distance that is robust to high levels of sparsity by using the matrix completion to handle the excessive zeros in the microbiome data (116). The PHILR transform of the ASV table was performed in R using the philr package (117). The selected distance matrices were explored and visualized by the principal coordinates analysis ( $\mathrm{PCoA})$.

Multivariate association analysis. The ASV table was collapsed at the genus level before running the multivariate association analysis. Bacterial taxa of very low abundance $(<0.01 \%)$ or low prevalence (present in $<25 \%$ of samples) were removed from the feature table. The microbial clades were then tested for significant associations with metadata of interest by MaAsLin2 (version, 0.99.12) (https: //huttenhower.sph.harvard.edu/maaslin2) in $\mathrm{R}$, using the default parameters. The results of the analysis are the associations of specific microbial clades with metadata, deconfounding the influence of other factors included in the model. Association was considered significant when the $q$-value was below 0.25 . Metadata included in the multivariate association testing are fixed factors Diet + Sample origin + distal intestine somatic index (DISI) + lamina propria cellularity (histological scores) + immune response (qPCR) + barrier function (qPCR), and random factors FishID + NetPen. FishID was nested in NetPen, and NetPen nested in Diet. Lamina propria cellularity reflects the severity of inflammation in the distal intestine. Based on the degree of cellular infiltration within the lamina propria, a value of normal, mild, moderate, marked or severe was assigned. To make the data appropriate for the association testing, the highly skewed five-category scores were collapsed into more balanced binary data, i.e., normal and abnormal. The immune-related genes included for the association testing were myeloid differentiation factor 88 (myd88), interleukin $1 \beta$ (ill $\beta$ ), interleukin 8 (il8), cluster of differentiation $3 \gamma \delta(c d 3 \gamma \delta)$, transforming growth factor $\beta 1$ (tgf $\beta 1$ ), interferon $\gamma$ (ifn $\gamma$ ), interleukin 17A (ill7a), fork-head box P3 (foxp3) and interleukin 10 (illo), whose expression levels were higher in the distal intestine of fish assigned abnormal regarding lamina propria cellularity. Since the expression levels of immune-related genes were highly correlated, we ran a principal component analysis (PCA) and extracted the first principle component (PC1) for the association testing to avoid multicollinearity and reduce the number of association testing. For genes relevant to the barrier function, which included claudin- 15 
bioRxiv preprint doi: https://doi.org/10.1101/2020.05.08.083899; this version posted May 24, 2020. The copyright holder for this preprint (which was not certified by peer review) is the author/funder, who has granted bioRxiv a license to display the preprint in perpetuity. It is made available under aCC-BY-ND 4.0 International license.

(cldn15), claudin-25b (cldn25b), zonula occludens 1 (zol), E-cadherin / cadherin 1 ( $c d h l$ ) and mucin-2 (тис2), we also used the PC1 of the PCA for the association testing based on the same considerations.

Statistics. All the statistical analyses were run in R except for the PERMANOVA, which was run in PRIMER v7. The differences in the alpha-diversity indices were compared using linear mixed-effects models via the lme4 package (118). Predictor variables in the models included the fixed effects Diet + Sample origin + Diet $x$ Sample origin, and the random effects FishID + NetPen. The models were validated by visual inspections of residual diagnostic plots generated by the ggResidpanel package (119). The statistical significance of fixed predictors was estimated by Type III ANOVA with Kenward-Roger's approximation of denominator degrees of freedom via the lmerTest package (120). When the interaction between the main effects was significant, conditional contrasts for the main effects were made via the emmeans package (121). To compare the differences in beta-diversity, we performed the PERMANOVA (122) using the same predictors included in the linear mixed-effects models. Terms with negative estimates for components of variation were sequentially removed from the model via term pooling, starting with the one showing the smallest mean squares. At each step, the model was reassessed whether more terms needed to be removed or not. Conditional contrasts for the main effects were constructed when their interaction was significant. Monte Carlo $p$ values were computed as well when the unique permutations for the terms in the PERMANOVA were small $(<100)$. The homogeneity of multivariate dispersions among groups was visually assessed with boxplots and was formally tested by the permutation test, PERMDISP (123), via the R package vegan (124). Multiple comparisons were adjusted by the Benjamini-Hochberg procedure where applicable. Differences were regarded as significant when $p$ $<0.05$.

Code availability. All the code for reproducing the results are available from the GitHub repository (https://github.com/yanxianl/Li_ AqF12-Microbiota_ASM_2020).

Data availability. Raw sequence data are deposited at the NCBI SRA database (https://www.ncbi.nlm. nih.gov/sra) under the BioProject PRJNA555355. Other raw data and sample metadata are available from the GitHub repository (https://github.com/ yanxianl/Li_AqF12-Microbiota_ASM_2020).

\section{Acknowledgments}

Y.L. was granted a scholarship from the China Scholarship Council to pursue his $\mathrm{PhD}$ degree at Norwegian University of Life Sciences. This work was a spin-off of the "AquaFly" project (grant number, 238997), funded by the Research Council of Norway and managed by the Institute of Marine
Research. Costs related to this study were covered by Norwegian University of Life Sciences. The funding agencies had no role in study design, data collection and interpretation, decision to publish or preparation of the manuscript.

The authors wish to thank Ellen K. Hage for organizing the sampling and technicians at the GIFAS for their committed animal care and supports during the sampling.

T.M.K. and Å.K. concepted and designed the study. Y.L., L.B. and K.G. participated in the sample collection. Y.L., L.B. and A.J.-T. carried out the laboratory works. Y.L. performed the bioinformatics, statistical analyses and data visualization. Y.L. and L.B. completed the first draft of the manuscript. All the authors read, revised and approved the final version of the manuscript.

We declare no conflicts of interest.

\section{Reference}

1. AK Ray, $\mathrm{K}$ Ghosh, and $\mathrm{E}$ Ringø. Enzyme-producing bacteria isolated from fish gut: a review. Aquac Nutr, 18(5):465-492, 2012. ISSN 1353-5773.

2. S. Falcinelli, S. Picchietti, A. Rodiles, L. Cossignani, D. L. Merrifield, A. R. Taddei, F. Maradonna, I. Olivotto, G. Gioacchini, and O. Carnevali. Lactobacillus rhamnosus lowers zebrafish lipid content by changing gut microbiota and host transcription of genes involved in lipid metabolism. Sci Rep, 5:9336, 2015. ISSN 2045-2322 (Electronic) 2045-2322 (Linking). doi: $10.1038 /$ srep09336.

3. I. Semova, J. D. Carten, J. Stombaugh, L. C. Mackey, R. Knight, S. A. Farber, and J. F. Rawls. Microbiota regulate intestinal absorption and metabolism of fatty acids in the zebrafish. Cell Host Microbe, 12(3):277-288, 2012. ISSN 1931-3128. doi: 10.1016/j.chom.2012.08.003

4. Mark Lyte and John F Cryan. Microbial endocrinology: the microbiota-gut-brain axis in health and disease, volume 817. Springer, 2014. ISBN 1493908979.

5. Seong Ran Jeon, Jocelyn Chai, Christiana Kim, and Christine H Lee. Current evidence for the management of inflammatory bowel diseases using fecal microbiota transplantation. Curr Infect Dis Rep, 20(8):21, 2018. ISSN 1523-3847.

6. D. N. Frank, A. L. St Amand, R. A. Feldman, E. C. Boedeker, N. Harpaz, and N. R. Pace. Molecular-phylogenetic characterization of microbial community imbalances in human inflammatory bowel diseases. Proc Natl Acad Sci U S A, 104(34):13780-5, 2007. ISSN 0027-8424 (Print) 0027-8424 (Linking). doi: 10.1073/pnas.0706625104.

7. Chaysavanh Manichanh, Lionel Rigottier-Gois, Elian Bonnaud, Karine Gloux, Eric Pelletier, Lionel Frangeul, Renaud Nalin, Cyrille Jarrin, Patrick Chardon, and Phillipe Marteau. Reduced diversity of faecal microbiota in crohn's disease revealed by a metagenomic approach. Gut, 55(2):205-211, 2006. ISSN 0017-5749.

8. N. Narula, Z. Kassam, Y. Yuan, J. F. Colombel, C. Ponsioen, W. Reinisch, and P. Moayyedi. Systematic review and meta-analysis: fecal microbiota transplantation for treatment of active ulcerative colitis. Inflamm Bowel Dis, 23(10):1702-1709, 2017. ISSN 1536-4844 (Electronic) 1078-0998 (Linking). doi: 10.1097/MIB.0000000000001228.

9. G. D. Wu, J. Chen, C. Hoffmann, K. Bittinger, Y. Y. Chen, S. A. Keilbaugh, M. Bewtra D. Knights, W. A. Walters, R. Knight, R. Sinha, E. Gilroy, K. Gupta, R. Baldassano, L. Nessel, H. Li, F. D. Bushman, and J. D. Lewis. Linking long-term dietary patterns with gut microbial enterotypes. Science, 334(6052):105-8, 2011. ISSN 1095-9203 (Electronic) 0036-8075 (Linking). doi: 10.1126/science.1208344.

10. Brian D Muegge, Justin Kuczynski, Dan Knights, Jose C Clemente, Antonio González, Luigi Fontana, Bernard Henrissat, Rob Knight, and Jeffrey I Gordon. Diet drives convergence in gut microbiome functions across mammalian phylogeny and within humans. Science, 332(6032):970-974, 2011. ISSN 0036-8075.

11. C. De Filippo, D. Cavalieri, M. Di Paola, M. Ramazzotti, J. B. Poullet, S. Massart, S. Collini, G. Pieraccini, and P. Lionetti. Impact of diet in shaping gut microbiota revealed by a comparative study in children from europe and rural africa. Proc Natl Acad Sci $U$ $S A, 107(33): 14691-6,2010$. ISSN 1091-6490 (Electronic) 0027-8424 (Linking). doi: 10.1073/pnas. 1005963107.

12. L. A. David, C. F. Maurice, R. N. Carmody, D. B. Gootenberg, J. E. Button, B. E. Wolfe, A. V. Ling, A. S. Devlin, Y. Varma, M. A. Fischbach, S. B. Biddinger, R. J. Dutton, and P. J. Turnbaugh. Diet rapidly and reproducibly alters the human gut microbiome. Nature, 505 (7484):559-63, 2014. ISSN 1476-4687 (Electronic) 0028-0836 (Linking). doi: 10.1038/ nature 12820 .

13. Z. Wang, E. Klipfell, B. J. Bennett, R. Koeth, B. S. Levison, B. Dugar, A. E. Feldstein, E. B. Britt, X. Fu, Y. M. Chung, Y. Wu, P. Schauer, J. D. Smith, H. Allayee, W. H. Tang, J. A. DiDonato, A. J. Lusis, and S. L. Hazen. Gut flora metabolism of phosphatidylcholine promotes cardiovascular disease. Nature, 472(7341):57-63, 2011. ISSN 1476-4687 (Electronic) 0028-0836 (Linking). doi: 10.1038/nature09922.

14. A. J. Hryckowian, W. Van Treuren, S. A. Smits, N. M. Davis, J. O. Gardner, D. M. Bouley, and J. L. Sonnenburg. Microbiota-accessible carbohydrates suppress clostridium difficile infection in a murine model. Nat Microbiol, 3(6):662-669, 2018. ISSN 2058-5276 (Electronic) 2058-5276 (Linking). doi: 10.1038/s41564-018-0150-6.

15. FAO. The State of World Fisheries and Aquaculture. FAO, Rome, Italy, 2018. ISBN 97892-5-130562-1.

16. Turid Synnøve Aas, Trine Ytrestøyl, and Torbjørn Åsgård. Utilization of feed resources in 
bioRxiv preprint doi: https://doi.org/10.1101/2020.05.08.083899; this version posted May 24, 2020. The copyright holder for this preprint (which was not certified by peer review) is the author/funder, who has granted bioRxiv a license to display the preprint in perpetuity. It is made available under aCC-BY-ND 4.0 International license.

the production of atlantic salmon (salmo salar) in norway: An update for 2016. Aquac Rep, 15:100216, 2019. ISSN 2352-5134.

17. María-José Sánchez-Muros, Fernando G. Barroso, and Francisco Manzano-Agugliaro. Insect meal as renewable source of food for animal feeding: a review. J Clean Prod, 65: 16-27, 2014. ISSN 09596526. doi: 10.1016/j.jclepro.2013.11.068.

18. Margareth Øverland and Anders Skrede. Yeast derived from lignocellulosic biomass as a sustainable feed resource for use in aquaculture. J Sci Food Agric, 97(3):733-742, 2016. ISSN 1097-0010.

19. K. Gajardo, A. Jaramillo-Torres, T. M. Kortner, D. L. Merrifield, J. Tinsley, A. M. Bakke, and A. Krogdahl. Alternative protein sources in the diet modulate microbiota and functionality in the distal intestine of atlantic salmon (salmo salar). Appl Environ Microbiol, 83(5):e0261516, 2017. ISSN 1098-5336 (Electronic) 0099-2240 (Linking). doi: 10.1128/AEM.02615-16.

20. Y. Jin, I. L. Angell, S. Rod Sandve, L. G. Snipen, Y. Olsen, and K. Rudi. Atlantic salmon raised with diets low in long-chain polyunsaturated $n-3$ fatty acids in freshwater have a mycoplasma-dominated gut microbiota at sea. Aquac Environ Interact, 11:31-39, 2019. ISSN 1869-215X. doi: 10.3354/aei00297.

21. Victor Schmidt, Linda Amaral-Zettler, John Davidson, Steven Summerfelt, and Christopher Good. Influence of fishmeal-free diets on microbial communities in atlantic salmon (salmo salar) recirculation aquaculture systems. Appl Environ Microbiol, 82(15):4470-4481, 2016. ISSN 0099-2240.

22. P. B. Eckburg, E. M. Bik, C. N. Bernstein, E. Purdom, L. Dethlefsen, M. Sargent, S. R. Gill, K. E. Nelson, and D. A. Relman. Diversity of the human intestinal microbial flora. Science, 308(5728):1635-8, 2005. ISSN 1095-9203 (Electronic) 0036-8075 (Linking). doi: $10.1126 /$ science. 1110591

23. K. Gajardo, A. Rodiles, T. M. Kortner, Å. Krogdahl, A. M. Bakke, D. L. Merrifield, and $\mathrm{H}$. Sorum. A high-resolution map of the gut microbiota in atlantic salmon (salmo salar): A basis for comparative gut microbial research. Sci Rep, 6:30893, 2016. ISSN 2045-2322 (Electronic) 2045-2322 (Linking). doi: 10.1038/srep30893.

24. Torey Looft, Heather K Allen, Brandi L Cantarel, Uri Y Levine, Darrell O Bayles, David P Alt, Bernard Henrissat, and Thaddeus B Stanton. Bacteria, phages and pigs: the effects of in-feed antibiotics on the microbiome at different gut locations. ISME J, 8(8):1566, 2014. ISSN 1751-7370.

25. Philip P Lyons, James F Turnbull, Karl A Dawson, and Margaret Crumlish. Exploring the microbial diversity of the distal intestinal lumen and mucosa of farmed rainbow trout oncorhynchus mykiss (walbaum) using next generation sequencing (ngs). Aquac Res, 48 (1):77-91, 2017. ISSN 1355-557X

26. D. Huyben, L. Sun, R. Moccia, A. Kiessling, J. Dicksved, and T. Lundh. Dietary live yeast and increased water temperature influence the gut microbiota of rainbow trout. J App Microbiol, 124(6):1377-1392, 2018. ISSN 1365-2672 (Electronic) 1364-5072 (Linking). doi: $10.1111 / j a m .13738$

27. A. Jaramillo-Torres, M. D. Rawling, A. Rodiles, H. E. Mikalsen, L. H. Johansen, J. Tinsley, T. Forberg, E. Aasum, M. Castex, and D. L. Merrifield. Influence of dietary supplementation of probiotic pediococcus acidilactici ma18/5m during the transition from freshwater to seawater on intestinal health and microbiota of atlantic salmon (salmo salar I.). Front Microbiol, 10:2243, 2019. ISSN 1664-302X (Print) 1664-302X (Linking). doi: 10.3389/fmicb.2019.02243.

28. S. Rimoldi, E. Gini, F. lannini, L. Gasco, and G. Terova. The effects of dietary insect meal from hermetia illucens prepupae on autochthonous gut microbiota of rainbow trout (oncorhynchus mykiss). Animals (Basel), 9(4), 2019. ISSN 2076-2615 (Print) 2076-2615 (Linking). doi: 10.3390/ani9040143.

29. Genciana Terova, Simona Rimoldi, Chiara Ascione, Elisabetta Gini, Chiara Ceccotti, and Laura Gasco. Rainbow trout (oncorhynchus mykiss) gut microbiota is modulated by insect meal from hermetia illucens prepupae in the diet. Rev Fish Biol Fish, 29(2):465-486, 2019. ISSN 0960-3166 1573-5184. doi: 10.1007/s11160-019-09558-y.

30. Leonardo Bruni, Ikram Belghit, Erik-Jan Lock, Giulia Secci, Cosimo Taiti, and Giuliana Parisi. Total replacement of dietary fish meal with black soldier fly (hermetia illucens) larvae does not impair physical, chemical or volatile composition of farmed atlantic salmon (salmo salar I.). J Sci Food Agric, 100(3):1038-1047, 2020. ISSN 0022-5142.

31. Yanxian Li, Trond M Kortner, Elvis M Chikwati, Ikram Belghit, Erik-Jan Lock, and Åshild Krogdahl. Total replacement of fish meal with black soldier fly (hermetia illucens) larvae meal does not compromise the gut health of atlantic salmon (salmo salar). Aquaculture, 520:734967, 2020. ISSN 0044-8486.

32. Ikram Belghit, Nina S Liland, Petter Gjesdal, Irene Biancarosa, Elisa Menchetti, Yanxian Li, Rune Waagbø, Åshild Krogdahl, and Erik-Jan Lock. Black soldier fly larvae meal can replace fish meal in diets of sea-water phase atlantic salmon (salmo salar). Aquaculture, 503:609-619, 2019. ISSN 0044-8486.

33. Carola E Dehler, Christopher J Secombes, and Samuel AM Martin. Seawater transfer alters the intestinal microbiota profiles of atlantic salmon (salmo salar I.). Sci Rep, 7(1): 13877, 2017. ISSN 2045-2322.

34. C. E. Dehler, C. J. Secombes, and S. A. M. Martin. Environmental and physiological factors shape the gut microbiota of atlantic salmon parr (salmo salar I.). Aquaculture, 467:149157, 2017. ISSN 0044-8486. doi: 10.1016/j.aquaculture.2016.07.017.

35. S. Gupta, A. Feckaninova, J. Lokesh, J. Koscova, M. Sorensen, J. Femandes, and V. Kiron Lactobacillus dominate in the intestine of atlantic salmon fed dietary probiotics. Fron Microbiol, 9, 2019. ISSN 1664-302X. doi: 10.3389/fmicb.2018.03247.

36. S. Gupta, J. Lokesh, Y. Abdelhafiz, P. Siriyappagouder, R. Pierre, M. Sorensen, J. M. O. Fernandes, and V. Kiron. Macroalga-derived alginate oligosaccharide alters intestinal bacteria of atlantic salmon. Front Microbiol, 10, 2019. ISSN 1664-302X. doi: 10.3389/fmicb.2019.02037.

37. Martin S Llewellyn, Philip McGinnity, Melanie Dionne, Justine Letourneau, Florian Thonier, Gary R Carvalho, Simon Creer, and Nicolas Derome. The biogeography of the atlantic salmon (salmo salar) gut microbiome. ISME J, 10(5):1280-1284, 2015. ISSN 1751-7362.

38. T. M. U. Webster, S. Consuegra, M. Hitchings, and C. G. de Leaniz. Interpopulation variation in the atlantic salmon microbiome reflects environmental and genetic diversity. App Environ Microbiol, 84(16):e00691-18, 2018. ISSN 0099-2240. doi: 10.1128/aem.00691-18.

39. C. Fogarty, C. M. Burgess, P. D. Cotter, R. Cabrera-Rubio, P. Whyte, C. Smyth, and D. J.
Bolton. Diversity and composition of the gut microbiota of atlantic salmon (salmo salar) farmed in irish waters. J Appl Microbiol, 127(3):648-657, 2019. ISSN 1364-5072. doi: 10.1111/jam.14291.

40. F. A. Godoy, C. D. Miranda, G. D. Wittwer, C. P. Aranda, and R. Calderon. High variability of levels of aliivibrio and lactic acid bacteria in the intestinal microbiota of farmed atlantic salmon salmo salar I. Ann Microbiol, 65(4):2343-2353, 2015. ISSN 1590-4261. doi: 10.1007/s13213-015-1076-3

41. C Karlsen, KF Ottem, Øyvind Jakobsen Brevik, M Davey, H Sørum, and HC Wintherarsen. The environmental and host-associated bacterial microbiota of arctic seawaterfarmed atlantic salmon with ulcerative disorders. J Fish Dis, 40(11):1645-1663, 2017. ISSN 1365-2761.

42. K. Z. Zarkasi, G. C. J. Abell, R. S. Taylor, C. Neuman, E. Hatje, M. L. Tamplin, M. Katouli, and J. P. Bowman. Pyrosequencing-based characterization of gastrointestinal bacteria of atlantic salmon (salmo salar I.) within a commercial mariculture system. J Appl Microbiol, 117(1):18-27, 2014. ISSN 1364-5072. doi: 10.1111/jam.12514.

43. Kamarul Zaman Zarkasi, Richard S Taylor, Guy CJ Abell, Mark L Tamplin, Brett D Glencross, and John P Bowman. Atlantic salmon (salmo salar I.) gastrointestinal microbial community dynamics in relation to digesta properties and diet. Microb Ecol, 71(3):589603, 2016. ISSN 0095-3628.

44. Henryk Urbanczyk, Jennifer C Ast, Melissa J Higgins, Jeremy Carson, and Paul V Dunlap. Reclassification of vibrio fischeri, vibrio logei, vibrio salmonicida and vibrio wodanis as aliivibrio fischeri gen. nov., comb. nov., aliivibrio logei comb. nov., aliivibrio salmonicida comb. nov. and aliivibrio wodanis comb. nov. Int J Syst Evol Microbiol, 57(12):2823-2829, 2007. ISSN 1466-5026.

45. Paul V Dunlap, Jennifer C Ast, Seishi Kimura, Atsushi Fukui, Tetsuo Yoshino, and Hiromitsu Endo. Phylogenetic analysis of host-symbiont specificity and codivergence in bioluminescent symbioses. Cladistics, 23(5):507-532, 2007. ISSN 0748-3007.

46. E Egidius, R Wiik, K Andersen, KA Hoff, and B Hjeltnes. Vibrio salmonicida sp. nov., a new fish pathogen. Int J Syst Evol Microbiol, 36(4):518-520, 1986. ISSN 1466-5026.

47. Tor Lunder, Henning Sørum, Gudmund Holstad, Arnold G Steigerwalt, Petter Mowinckel, and Don J Brenner. Phenotypic and genotypic characterization of vibrio viscosus sp. nov. and vibrio wodanis $\mathrm{sp}$. nov. isolated from atlantic salmon (salmo salar) with 'winter ulcer'. Int J Syst Evol Microbiol, 50(2):427-450, 2000. ISSN 1466-5026.

48. J. F. Anderson, R. C. Johnson, L. A. Magnarelli, F. W. Hyde, and T. G. Andreadis. New infectious spirochete isolated from short-tailed shrews and white-footed mice. J Clin Microbiol, 25(8):1490-4, 1987. ISSN 0095-1137 (Print) 0095-1137 (Linking)

49. R. M. Brown, G. D. Wiens, and I. Salinas. Analysis of the gut and gill microbiome of resistant and susceptible lines of rainbow trout (oncorhynchus mykiss). Fish Shellfish Immunol, 86:497-506, 2019. ISSN 1095-9947 (Electronic) 1050-4648 (Linking). doi: 10. 1016/j.fsi.2018.11.079.

50. ST Tapia-Paniagua, S Vidal, C Lobo, MJ Prieto-Álamo, J Jurado, H Cordero, R Cerezuela, I García de la Banda, MA Esteban, and MC Balebona. The treatment with the probiotic shewanella putrefaciens pdp11 of specimens of solea senegalensis exposed to high stocking densities to enhance their resistance to disease. Fish Shellfish Immunol, 41(2): 209-221, 2014. ISSN 1050-4648.

51. WE Holben, P Williams, M Saarinen, LK Särkilahti, and JHA Apajalahti. Phylogenetic analysis of intestinal microflora indicates a novel mycoplasma phylotype in farmed and wild salmon. Microb Ecol, 44(2):175-185, 2002. ISSN 0095-3628.

52. S. Razin, D. Yogev, and Y. Naot. Molecular biology and pathogenicity of mycoplasmas. Microbiol Mol Biol Rev, 62(4):1094-156, 1998. ISSN 1092-2172 (Print) 1092-2172 (Linking).

53. J. Dennis Pollack, Marshall V. Williams, and Ronald N. McElhaney. The comparative metabolism of the mollicutes (mycoplasmas): the utility for taxonomic classification and the relationship of putative gene annotation and phylogeny to enzymatic function in the smallest free-living cells. Crit Rev Microbiol, 23(4):269-354, 1997. ISSN 1040-841X.

54. P. Van den Abbeele, T. Van de Wiele, W. Verstraete, and S. Possemiers. The host selects mucosal and luminal associations of coevolved gut microorganisms: a novel concept. FEMS Microbiol Rev, 35(4):681-704, 2011. ISSN 1574-6976 (Electronic) 0168-6445 (Linking). doi: 10.1111/j.1574-6976.2011.00270.x

55. MJ Kennedy, DK Rosnick, RG Ulrich, and RJ Yancey Jr. Association of treponema hyodysenteriae with porcine intestinal mucosa. J Gen Microbiol, 134(6):1565-1576, 1988. ISSN 1350-0872.

56. JA Milner and R Sellwood. Chemotactic response to mucin by serpulina hyodysenteriae and other porcine spirochetes: potential role in intestinal colonization. Infect Immun, 62 (9):4095-4099, 1994. ISSN 0019-9567.

57. Nancy A Witters and Gerald E Duhamel. Motility-regulated mucin association of Serpulina pilosicoli, the agent of colonic spirochetosis of humans and animals, volume 473, pages 199-205. Springer, 1999.

58. Leonardo Bruni, Roberta Pastorelli, Carlo Viti, Laura Gasco, and Giuliana Parisi. Characterisation of the intestinal microbial communities of rainbow trout (oncorhynchus mykiss) fed with hermetia illucens (black soldier fly) partially defatted larva meal as partial dietary protein source. Aquaculture, 487:56-63, 2018. ISSN 0044-8486.

59. David Huyben, Aleksandar Vidaković, Sofia Werner Hallgren, and Markus Langeland. High-throughput sequencing of gut microbiota in rainbow trout (oncorhynchus mykiss) fed larval and pre-pupae stages of black soldier fly (hermetia illucens). Aquaculture, 500: 485-491, 2019. ISSN 0044-8486.

60. L. Borrelli, L. Coretti, L. Dipineto, F. Bovera, F. Menna, L. Chiariotti, A. Nizza, F. Lembo, and $A$. Fioretti. Insect-based diet, a promising nutritional source, modulates gut microbiota composition and scfas production in laying hens. Sci Rep, 7(1):1-11, 2017. ISSN 20452322. doi: 10.1038/s41598-017-16560-6.

61. K. Kawasaki, Y. Hashimoto, A. Hori, T. Kawasaki, H. Hirayasu, S. Iwase, A. Hashizume, A. Ido, C. Miura, T. Miura, S. Nakamura, T. Seyama, Y. Matsumoto, K. Kasai, and Y. Fujitani. Evaluation of black soldier fly (hermetia illucens) larvae and pre-pupae raised on household organic waste, as potential ingredients for poultry feed. Animals (Basel), 9(3), 2019. ISSN 2076-2615. doi: 10.3390/ani9030098.

62. A. Jozefiak, S. Nogales-Merida, Z. Mikolajczak, M. Rawski, B. Kieronczyk, and J. Mazurkiewicz. The utilization of full-fat insect meal in rainbow trout (oncorhynchus 
bioRxiv preprint doi: https://doi.org/10.1101/2020.05.08.083899; this version posted May 24, 2020. The copyright holder for this preprint (which was not certified by peer review) is the author/funder, who has granted bioRxiv a license to display the preprint in perpetuity. It is made available under aCC-BY-ND 4.0 International license.

mykiss) nutrition: The effects on growth performance, intestinal microbiota and gastrointestinal tract histomorphology. Ann Anim Sci, 19(3):747-765, 2019. ISSN 2300-8733. doi: 10.2478/aoas-2019-0020

63. A. Jozefiak, S. Nogales-Merida, M. Rawski, B. Kieronczyk, and J. Mazurkiewicz. Effects of insect diets on the gastrointestinal tract health and growth performance of siberian sturgeon (acipenser baerii brandt, 1869). BMC Microbiol, 15(1), 2019. doi: 10.1186/s12917-019-2070-y.

64. C. L. Jiang, W. Z. Jin, X. H. Tao, Q. Zhang, J. Zhu, S. Y. Feng, X. H. Xu, H. Y. Li, Z. H. Wang, and Z. J. Zhang. Black soldier fly larvae (hermetia illucens) strengthen the metabolic function of food waste biodegradation by gut microbiome. Microb Biotechnol, 12(3):528543, 2019. ISSN 1751-7915. doi: 10.1111/1751-7915.13393.

65. Daniele Bruno, Marco Bonelli, Francesca De Filippis, Ilaria Di Lelio, Gianluca Tettamanti, Morena Casartelli, Danilo Ercolini, and Silvia Caccia. The intestinal microbiota of hermetia illucens larvae is affected by diet and shows a diverse composition in the different midgut regions. Appl Environ Microbiol, 85(2):e01864-18, 2019. ISSN 0099-2240.

66. Enya Wynants, Lotte Frooninckx, Sam Crauwels, Christel Verreth, Jeroen De Smet, Christoph Sandrock, Jens Wohlfahrt, Jeroen Van Schelt, Stefaan Depraetere, and Bart Lievens. Assessing the microbiota of black soldier fly larvae (hermetia illucens) reared on organic waste streams on four different locations at laboratory and large scale. Microb Ecol, 77(4):913-930, 2019. ISSN 0095-3628.

67. Longyu Zheng, Tawni L Crippen, Baneshwar Singh, Aaron M Tarone, Scot Dowd, Ziniu Yu, Thomas K Wood, and Jeffery K Tomberlin. A survey of bacterial diversity from successive life stages of black soldier fly (diptera: Stratiomyidae) by using $16 \mathrm{~s}$ rdna pyrosequencing. J Med Entomol, 50(3):647-658, 2013. ISSN 1938-2928.

68. J. B. Emerson, R. I. Adams, C. M. B. Roman, B. Brooks, D. A. Coil, K. Dahlhausen, H. H. Ganz, E. M. Hartmann, T. Hsu, N. B. Justice, I. G. Paulino-Lima, J. C. Luongo, D. S. Lymperopoulou, C. Gomez-Silvan, B. Rothschild-Mancinelli, M. Balk, C. Huttenhower, A. Nocker, P. Vaishampayan, and L. J. Rothschild. Schrodinger's microbes: Tools for distinguishing the living from the dead in microbial ecosystems. Microbiome, 5(1):86, 2017. ISSN 2049-2618. doi: 10.1186/s40168-017-0285-3.

69. Sara Beier and Stefan Bertilsson. Bacterial chitin degradation-mechanisms and ecophysiological strategies. Front Microbiol, 4:149, 2013. ISSN 1664-302X

70. RM Cody. Distribution of chitinase and chitobiase in bacillus. Curr Microbiol, 19(4):201205, 1989. ISSN 0343-8651.

71. F. Askarian, Z. G. Zhou, R. E. Olsen, S. Sperstad, and E. Ringo. Culturable autochthonous gut bacteria in atlantic salmon (salmo salar I.) fed diets with or without chitin. characterization by $16 \mathrm{~s}$ rrna gene sequencing, ability to produce enzymes and in vitro growth inhibition of four fish pathogens. Aquaculture, 326:1-8, 2012. ISSN 0044-8486. doi: 10.1016/j.aquaculture.2011.10.016.

72. C. L. Maynard, C. O. Elson, R. D. Hatton, and C. T. Weaver. Reciprocal interactions of the intestinal microbiota and immune system. Nature, 489(7415):231-41, 2012. ISSN 1476-4687 (Electronic) 0028-0836 (Linking). doi: 10.1038/nature11551.

73. Michael R. McLaren, Amy D. Willis, and Benjamin J. Callahan. Consistent and correctable bias in metagenomic sequencing experiments. Elife, 8, 2019.

74. J Paul Brooks, David J Edwards, Michael D Harwich, Maria C Rivera, Jennifer M Fettweis, Myrna G Serrano, Robert A Reris, Nihar U Sheth, Bernice Huang, and Philippe Girerd. The truth about metagenomics: quantifying and counteracting bias in $16 \mathrm{~s}$ rrna studies. BMC Microbiol, 15(1):66, 2015. ISSN 1471-2180.

75. Rashmi Sinha, Christian C Abnet, Owen White, Rob Knight, and Curtis Huttenhower. The microbiome quality control project: baseline study design and future directions. Genome Biol, 16(1):276, 2015. ISSN 1474-760X.

76. Paul I Costea, Georg Zeller, Shinichi Sunagawa, Eric Pelletier, Adriana Alberti, Florence Levenez, Melanie Tramontano, Marja Driessen, Rajna Hercog, and Ferris-Elias Jung. Towards standards for human fecal sample processing in metagenomic studies. Nat Biotechnol, 35(11):1069, 2017. ISSN 1546-1696.

77. Alba Santiago, Suchita Panda, Griet Mengels, Xavier Martinez, Fernando Azpiroz, Joel Dore, Francisco Guarner, and Chaysavanh Manichanh. Processing faecal samples: a step forward for standards in microbial community analysis. BMC Microbiol, 14(1):112, 2014. ISSN 1471-2180.

78. V. Lazarevic, N. Gaia, M. Girard, and J. Schrenzel. Decontamination of 16 s rna gene amplicon sequence datasets based on bacterial load assessment by qpcr. BMC Microbiol, 16(1):73, 2016. ISSN 1471-2180 (Electronic) 1471-2180 (Linking). doi: 10.1186/ s12866-016-0689-4

79. D. Kim, C. E. Hofstaedter, C. Zhao, L. Mattei, C. Tanes, E. Clarke, A. Lauder, S. SherrillMix, C. Chehoud, J. Kelsen, M. Conrad, R. G. Collman, R. Baldassano, F. D. Bushman, and K. Bittinger. Optimizing methods and dodging pitfalls in microbiome research Microbiome, 5(1):52, 2017. ISSN 2049-2618 (Electronic) 2049-2618 (Linking). doi: 10.1186/s40168-017-0267-5.

80. E. Jousselin, A. L. Clamens, M. Galan, M. Bernard, S. Maman, B. Gschloessl, G. Duport, A. S. Meseguer, F. Calevro, and A. Coeur d'acier. Assessment of a $16 \mathrm{~s}$ rrna amplicon illumina sequencing procedure for studying the microbiome of a symbiont-rich aphid genus. Mol Ecol Resour, 16(3):628-40, 2016. ISSN 1755-0998 (Electronic) 1755-098X (Linking). doi: 10.1111/1755-0998.12478

81. T. Jost, C. Lacroix, C. Braegger, and C. Chassard. Assessment of bacterial diversity in breast milk using culture-dependent and culture-independent approaches. $\mathrm{Br} J$ Nutr, 110(7):1253-62, 2013. ISSN 1475-2662 (Electronic) 0007-1145 (Linking). doi: 10.1017/S0007114513000597.

82. J. Jervis-Bardy, L. E. X. Leong, S. Marri, R. J. Smith, J. M. Choo, H. C. Smith-Vaughan, E. Nosworthy, P. S. Morris, S. O'Leary, G. B. Rogers, and R. L. Marsh. Deriving accurate microbiota profiles from human samples with low bacterial content through postsequencing processing of illumina miseq data. Microbiome, 3(1):19, 2015. ISSN 20492618. doi: ARTN1910.1186/s40168-015-0083-8.

83. A. Glassing, S. E. Dowd, S. Galandiuk, B. Davis, and R. J. Chiodini. Inherent bacteria dna contamination of extraction and sequencing reagents may affect interpretation of $\mathrm{mi}-$ crobiota in low bacterial biomass samples. Gut Pathog, 8(1):24, 2016. ISSN 1757-4749. doi: ARTN2410.1186/s13099-016-0103-7.
84. N. M. Davis, D. M. Proctor, S. P. Holmes, D. A. Relman, and B. J. Callahan. Simple statistical identification and removal of contaminant sequences in marker-gene and metagenomics data. Microbiome, 6(1):226, 2018. ISSN 2049-2618 (Electronic) 2049-2618 (Link ing). doi: 10.1186/s40168-018-0605-2.

85. S. J. Salter, M. J. Cox, E. M. Turek, S. T. Calus, W. O. Cookson, M. F. Moffatt, P. Turner J. Parkhill, N. J. Loman, and A. W. Walker. Reagent and laboratory contamination can critically impact sequence-based microbiome analyses. BMC Biol, 12:87, 2014. ISSN 1741-7007 (Electronic) 1741-7007 (Linking). doi: 10.1186/s12915-014-0087-z.

86. L. A. Kulakov, M. B. McAlister, K. L. Ogden, M. J. Larkin, and J. F. O'Hanlon. Analysis of bacteria contaminating ultrapure water in industrial systems. Appl Environ Microbiol, 68 (4):1548-55, 2002. ISSN 0099-2240 (Print) 0099-2240 (Linking). doi: 10.1128/aem.68.4 $1548-1555.2002$.

87. N. Grahn, M. Olofsson, K. Ellnebo-Svedlund, H. J. Monstein, and J. Jonasson. Identification of mixed bacterial dna contamination in broad-range pcr amplification of $16 \mathrm{~s}$ rdna v1 and v3 variable regions by pyrosequencing of cloned amplicons. FEMS Microbiol Lett, 219(1):87-91, 2003. ISSN 0378-1097 (Print) 0378-1097 (Linking). doi: 10.1016/S0378-1097(02)01190-4

88. L. Cantas, T. W. K. Fraser, P. G. Fjelldal, I. Mayer, and H. Sorum. The culturable intestina microbiota of triploid and diploid juvenile atlantic salmon (salmo salar) - a comparison of composition and drug resistance. BMC Vet Res, 7(1):71, 2011. ISSN 1746-6148. doi: 10.1186/1746-6148-7-71

89. P. Navarrete, P. Fuentes, L. De la Fuente, L. Barros, F. Magne, R. Opazo, C. Ibacache, R. Espejo, and J. Romero. Short-term effects of dietary soybean meal and lactic acid bacteria on the intestinal morphology and microbiota of atlantic salmon (salmo salar). Aquac Nutr, 19(5):827-836, 2013. ISSN 1353-5773. doi: 10.1111/anu.12047.

90. E. Hatje, C. Neuman, H. Stevenson, J. P. Bowman, and M. Katouli. Population dynamics of vibrio and pseudomonas species isolated from farmed tasmanian atlantic salmon (salmo salar I.): a seasonal study. Microb Ecol, 68(4):679-687, 2014. ISSN 0095-3628. doi: 10.1007/s00248-014-0462-x.

91. X. P. He, S. R. Chaganti, and D. D. Heath. Population-specific responses to interspecific competition in the gut microbiota of two atlantic salmon (salmo salar) populations. Microb Ecol, 75(1):140-151, 2018. ISSN 0095-3628. doi: 10.1007/s00248-017-1035-6.

92. M. Laurence, C. Hatzis, and D. E. Brash. Common contaminants in next-generation se quencing that hinder discovery of low-abundance microbes. PLoS One, 9(5):e97876, 2014. ISSN 1932-6203 (Electronic) 1932-6203 (Linking). doi: 10.1371/journal.pone. 0097876.

93. Abigail P. Lauder, Aoife M. Roche, Scott Sherrill-Mix, Aubrey Bailey, Alice L. Laughlin, Kyle Bittinger, Rita Leite, Michal A. Elovitz, Samuel Parry, and Frederic D. Bushman. Comparison of placenta samples with contamination controls does not provide evidence for a distinct placenta microbiota. Microbiome, 4:29, 2016

94. H. A. Barton, N. M. Taylor, B. R. Lubbers, and A. C. Pemberton. Dna extraction from low-biomass carbonate rock: an improved method with reduced contamination and the low-biomass contaminant database. J Microbiol Methods, 66(1):21-31, 2006. ISSN 01677012 (Print) 0167-7012 (Linking). doi: 10.1016/j.mimet.2005.10.005.

95. L. S. Weyrich, A. G. Farrer, R. Eisenhofer, L. A. Arriola, J. Young, C. A. Selway, M. Handsley-Davis, C. J. Adler, J. Breen, and A. Cooper. Laboratory contamination ove time during low-biomass sample analysis. Mol Ecol Resour, 19(4):982-996, 2019. ISSN 1755-0998 (Electronic) 1755-098X (Linking). doi: 10.1111/1755-0998.13011.

96. M. A. Tanner, B. M. Goebel, M. A. Dojka, and N. R. Pace. Specific ribosomal dna sequences from diverse environmental settings correlate with experimental contaminants Appl Environ Microbiol, 64(8):3110-3, 1998. ISSN 0099-2240 (Print) 0099-2240 (Linking)

97. R. Eisenhofer, J. J. Minich, C. Marotz, A. Cooper, R. Knight, and L. S. Weyrich. Contamination in low microbial biomass microbiome studies: issues and recommendations. Trends Microbiol, 27(2):105-117, 2019. ISSN 1878-4380 (Electronic) 0966-842X (Linking). doi: 10.1016/j.tim.2018.11.003.

98. M. C. de Goffau, S. Lager, S. J. Salter, J. Wagner, A. Kronbichler, D. S. Charnock-Jones, S. J. Peacock, G. C. S. Smith, and J. Parkhill. Recognizing the reagent microbiome. Nat Microbiol, 3(8):851-853, 2018. ISSN 2058-5276 (Electronic) 2058-5276 (Linking). doi: 10.1038/s41564-018-0202-y.

99. G. Roeselers, E. K. Mittge, W. Z. Stephens, D. M. Parichy, C. M. Cavanaugh, K. Guillemin and J. F. Rawls. Evidence for a core gut microbiota in the zebrafish. ISME J, 5(10):1595608, 2011. ISSN 1751-7370 (Electronic) 1751-7362 (Linking). doi: 10.1038/ismej.2011.38.

100. D. Vandeputte, G. Kathagen, K. D'Hoe, S. Vieira-Silva, M. Valles-Colomer, J. Sabino, J. Wang, R. Y. Tito, L. De Commer, Y. Darzi, S. Vermeire, G. Falony, and J. Raes. Quantitative microbiome profiling links gut community variation to microbial load. $\mathrm{Na}$ ture, 551(7681):507-511, 2017. ISSN 1476-4687 (Electronic) 0028-0836 (Linking). do: 10.1038 /nature 24460.

101. C. A. Ramseier, J. S. Kinney, A. E. Herr, T. Braun, J. V. Sugai, C. A. Shelburne, L. A. Rayburn, H. M. Tran, A. K. Singh, and W. V. Giannobile. Identification of pathogen and host-response markers correlated with periodontal disease. J Periodontol, 80(3):436-46, 2009. ISSN 0022-3492 (Print) 0022-3492 (Linking). doi: 10.1902/jop.2009.080480.

102. Randy Rasmussen. Quantification on the LightCycler, pages 21-34. Springer, 2001.

103. J. Hellemans, G. Mortier, A. De Paepe, F. Speleman, and J. Vandesompele. qbase relative quantification framework and software for management and automated analysis of realtime quantitative pcr data. Genome Biol, 8(2):R19, 2007. ISSN 1474-760X (Electronic) 1474-7596 (Linking). doi: 10.1186/gb-2007-8-2-r19.

104. I Illumina. 16s metagenomic sequencing library preparation. Preparing 165 Ribosomal RNA Gene Amplicons for the Illumina MiSeq System, pages 1-28, 2013.

105. R Core Team et al. R: A language and environment for statistical computing. 2013

106. Benjamin J Callahan, Paul J McMurdie, Michael J Rosen, Andrew W Han, Amy Jo A Johnson, and Susan P Holmes. Dada2: high-resolution sample inference from illumina amplicon data. Nat Methods, 13(7):581-583, 2016. ISSN 1548-7091.

107. Evan Bolyen, Jai Ram Rideout, Matthew R. Dillon, Nicholas A. Bokulich, Christian C. Abnet, Gabriel A. Al-Ghalith, Harriet Alexander, Eric J. Alm, Manimozhiyan Arumugam, Francesco Asnicar, Yang Bai, Jordan E. Bisanz, Kyle Bittinger, Asker Brejnrod, Colin J. Brislawn, C. Titus Brown, Benjamin J. Callahan, Andrés Mauricio Caraballo-Rodríguez, 
bioRxiv preprint doi: https://doi.org/10.1101/2020.05.08.083899; this version posted May 24, 2020. The copyright holder for this preprint (which was not certified by peer review) is the author/funder, who has granted bioRxiv a license to display the preprint in perpetuity. It is made available under aCC-BY-ND 4.0 International license.

John Chase, Emily K. Cope, Ricardo Da Silva, Christian Diener, Pieter C. Dorrestein Gavin M. Douglas, Daniel M. Durall, Claire Duvallet, Christian F. Edwardson, Madeleine Ernst, Mehrbod Estaki, Jennifer Fouquier, Julia M. Gauglitz, Sean M. Gibbons, Deanna L. Gibson, Antonio Gonzalez, Kestrel Gorlick, Jiarong Guo, Benjamin Hillmann, Susan Holmes, Hannes Holste, Curtis Huttenhower, Gavin A. Huttley, Stefan Janssen, Alan K. Jarmusch, Lingjing Jiang, Benjamin D. Kaehler, Kyo Bin Kang, Christopher R. Keefe, Paul Keim, Scott T. Kelley, Dan Knights, Irina Koester, Tomasz Kosciolek, Jorden Kreps, Morgan G. I. Langille, Joslynn Lee, Ruth Ley, Yong-Xin Liu, Erikka Loftfield, Catherine Lozupone, Massoud Maher, Clarisse Marotz, Bryan D. Martin, Daniel McDonald, Lauren J. Mclver, Alexey V. Melnik, Jessica L. Metcalf, Sydney C. Morgan, Jamie T. Morton, Ahmad Turan Naimey, Jose A. Navas-Molina, Louis Felix Nothias, Stephanie B. Orchanian, Talima Pearson, Samuel L. Peoples, Daniel Petras, Mary Lai Preuss, Elmar Pruesse, Lasse Buur Rasmussen, Adam Rivers, Michael S. Robeson, Patrick Rosenthal, Nicola Segata, Michael Shaffer, Arron Shiffer, Rashmi Sinha, Se Jin Song, John R. Spear, Austin D. Swafford, Luke R. Thompson, Pedro J. Torres, Pauline Trinh, Anupriya Tripathi, Peter J. Turnbaugh, Sabah UI-Hasan, Justin J. J. van der Hooft, Fernando Vargas, Yoshiki Vázquez-Baeza, Emily Vogtmann, Max von Hippel, William Walters, et al. Reproducible, interactive, scalable and extensible microbiome data science using qiime 2. Nat Biotechnol, 37(8):852857, 2019. ISSN 1546-1696. doi: 10.1038/s41587-019-0209-9.

108. Nicholas A Bokulich, Benjamin D Kaehler, Jai Ram Rideout, Matthew Dillon, Evan Bolyen, Rob Knight, Gavin A Huttley, and J Gregory Caporaso. Optimizing taxonomic classification of marker-gene amplicon sequences with qiime 2's q2-feature-classifier plugin. Microbiome, 6(1):90, 2018. ISSN 2049-2618.

109. C. Quast, E. Pruesse, P. Yilmaz, J. Gerken, T. Schweer, P. Yarza, J. Peplies, and F. O. Glockner. The silva ribosomal rna gene database project: improved data processing and web-based tools. Nucleic Acids Res, 41 (Database issue):D590-6, 2013. ISSN $1362-4962$ (Electronic) 0305-1048 (Linking). doi: 10.1093/nar/gks1219.

110. Stefan Janssen, Daniel McDonald, Antonio Gonzalez, Jose A Navas-Molina, Lingjing Jiang, Zhenjiang Zech Xu, Kevin Winker, Deborah M Kado, Eric Orwoll, and Mark Manary. Phylogenetic placement of exact amplicon sequences improves associations with clinical information. mSystems, 3(3):e00021-18, 2018. ISSN 2379-5077.

111. Jordan E Bisanz. qiime2r: Importing qiime2 artifacts and associated data into $r$ sessions. 2018. v0.99.

112. Paul J McMurdie and Susan Holmes. phyloseq: an $r$ package for reproducible interactive analysis and graphics of microbiome census data. 2013. ISSN 1932-6203.

113. Leo Lahti, Sudarshan Shetty, Tineka Blake, and Jarkko Salojarvi. Microbiome r package. Tools Microbiome Anal. R., 2017.

114. S. W. Kembel, P. D. Cowan, M. R. Helmus, W. K. Cornwell, H. Morlon, D. D. Ackerly, S. P. Blomberg, and C. O. Webb. Picante: R tools for integrating phylogenies and ecology. Bioinformatics, 26(11):1463-4, 2010. ISSN 1367-4811 (Electronic) 1367-4803 (Linking). doi: 10.1093/bioinformatics/btq166.

115. Sophie Weiss, Zhenjiang Zech Xu, Shyamal Peddada, Amnon Amir, Kyle Bittinger, Antonio Gonzalez, Catherine Lozupone, Jesse R Zaneveld, Yoshiki Vázquez-Baeza, and Amanda Birmingham. Normalization and microbial differential abundance strategies depend upon data characteristics. Microbiome, 5(1):27, 2017. ISSN 2049-2618.

116. C. Martino, J. T. Morton, C. A. Marotz, L. R. Thompson, A. Tripathi, R. Knight, and K. Zengler. A novel sparse compositional technique reveals microbial perturbations. mSystems, 4(1):e00016-19, 2019. ISSN 2379-5077 (Print) 2379-5077 (Linking). doi 10.1128/mSystems.00016- 19

117. Justin D Silverman, Alex D Washburne, Sayan Mukherjee, and Lawrence A David. A phylogenetic transform enhances analysis of compositional microbiota data. Elife, 6:e21887, 2017. ISSN 2050-084X.

118. Douglas Bates, Martin Mächler, Ben Bolker, and Steve Walker. Fitting linear mixed-effects models using Ime4. J Stat Softw, 67(1):1-48, 2015.

119. Katherine Goode and Kathleen Rey. ggresidpanel: Panels and interactive versions of diagnostic plots using 'ggplot2'. 2019. R package version 0.3.0.

120. Alexandra Kuznetsova, Per B Brockhoff, and Rune Haubo Bojesen Christensen. Imertest package: tests in linear mixed effects models. J Stat Softw, 82(13), 2017. ISSN 15487660 .

121. Russell Lenth. emmeans: Estimated marginal means, aka least-squares means. 2020. R package version 1.4.6

122. Marti $\mathrm{J}$ Anderson. A new method for non-parametric multivariate analysis of variance. Austral Ecol, 26(1):32-46, 2001. ISSN 1442-9993.

123. Marti J Anderson. Distance-based tests for homogeneity of multivariate dispersions. Biometrics, 62(1):245-253, 2006. ISSN 1541-0420.

124. Jari Oksanen, F. Guillaume Blanchet, Michael Friendly, Roeland Kindt, Pierre Legendre, Dan McGlinn, Peter R. Minchin, R. B. O'Hara, Gavin L. Simpson, Peter Solymos, M. Henry H. Stevens, Eduard Szoecs, and Helene Wagner. vegan: Community ecology package. 2019. R package version 2.5-6. 
bioRxiv preprint doi: https://doi.org/10.1101/2020.05.08.083899; this version posted May 24, 2020. The copyright holder for this preprint (which

was not certified by peer review) is the author/funder, who has granted bioRxiv a license to display the preprint in perpetuity. It is made available under ACC-BY-ND 4.0 International license.

\section{Supplementary Note 1: Supplemental tables}

The supplemental tables are available on bioRXiv:

- Table S1. Contaminating features removed from the ASV table.

- Table S2. The prevalence of core taxa in different sample types. 
bioRxiv preprint doi: https://doi.org/10.1101/2020.05.08.083899; this version posted May 24, 2020. The copyright holder for this preprint (which

was not certified by peer review) is the author/funder, who has granted bioRxiv a license to display the preprint in perpetuity. It is made available under aCC-BY-ND 4.0 International license.

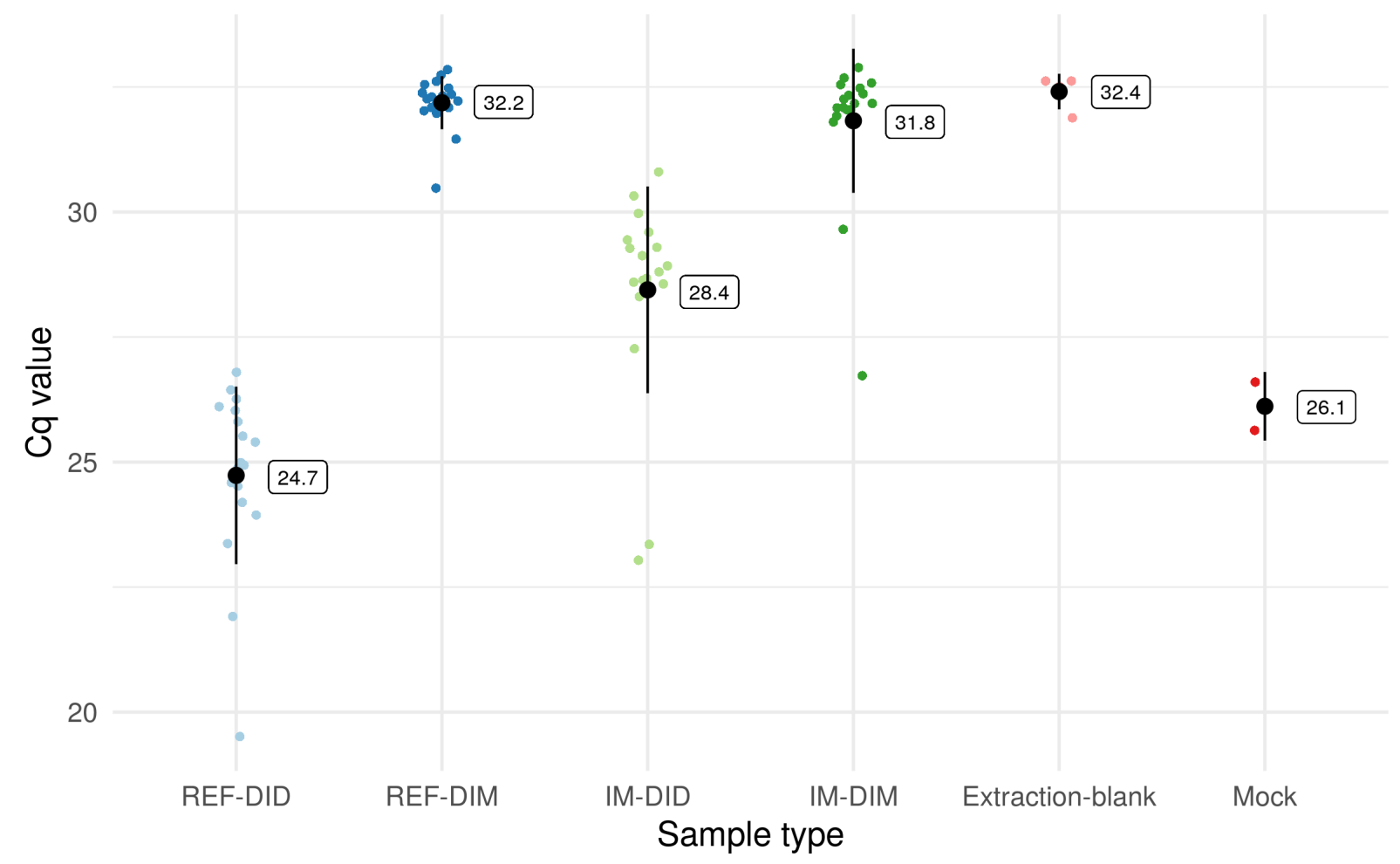

Fig. S1. Quantification of bacterial 16S rRNA gene in different sample types using qPCR. Since the Cq values of most mucosaassociated samples were out of the linear range of the standard curve, the Cq value was used as a proxy of $16 \mathrm{~S}$ rRNA gene quantity which is reliable for the screening of contaminant sequences. Data are presented as mean \pm 1 standard deviation overlaying the raw data points. Abbreviations: REF, reference diet; IM, insect meal diet; DID, distal intestine digesta; DIM, distal intestine mucosa. 
bioRxiv preprint doi: https://doi.org/10.1101/2020.05.08.083899; this version posted May 24, 2020. The copyright holder for this preprint (which was not certified by peer review) is the author/funder, who has granted bioRxiv a license to display the preprint in perpetuity. It is made available under aCC-BY-ND 4.0 International license.
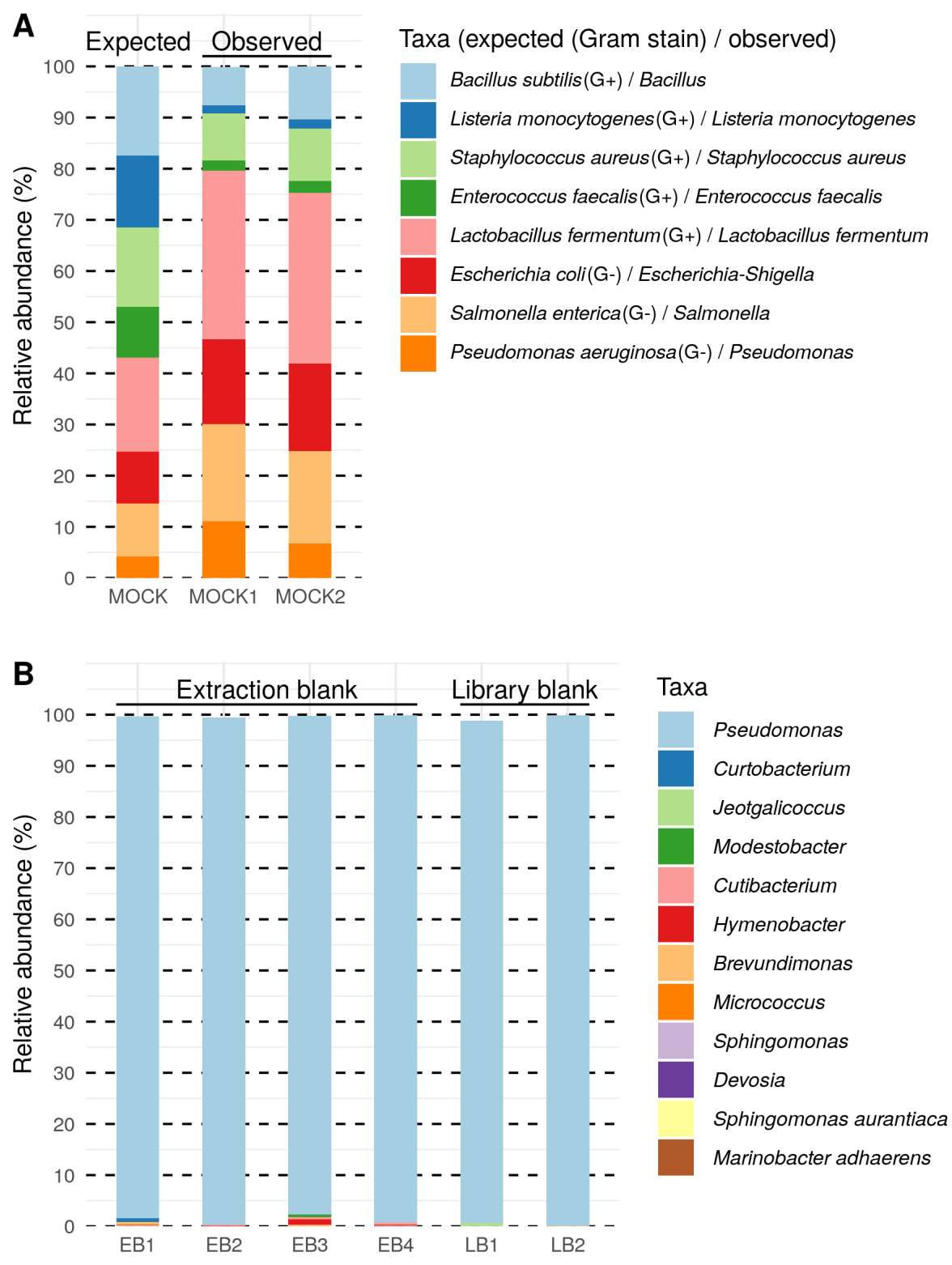

Fig. S2. Taxonomic profile of the mock $(A)$ and contaminating features in the negative controls (B). The lowest level of taxonomic ranks was displayed for each taxon. EB, extraction blank; LB, library blank. 
bioRxiv preprint doi: https://doi.org/10.1101/2020.05.08.083899; this version posted May 24, 2020. The copyright holder for this preprint (which was not certified by peer review) is the author/funder, who has granted bioRxiv a license to display the preprint in perpetuity. It is made available under aCC-BY-ND 4.0 International license.
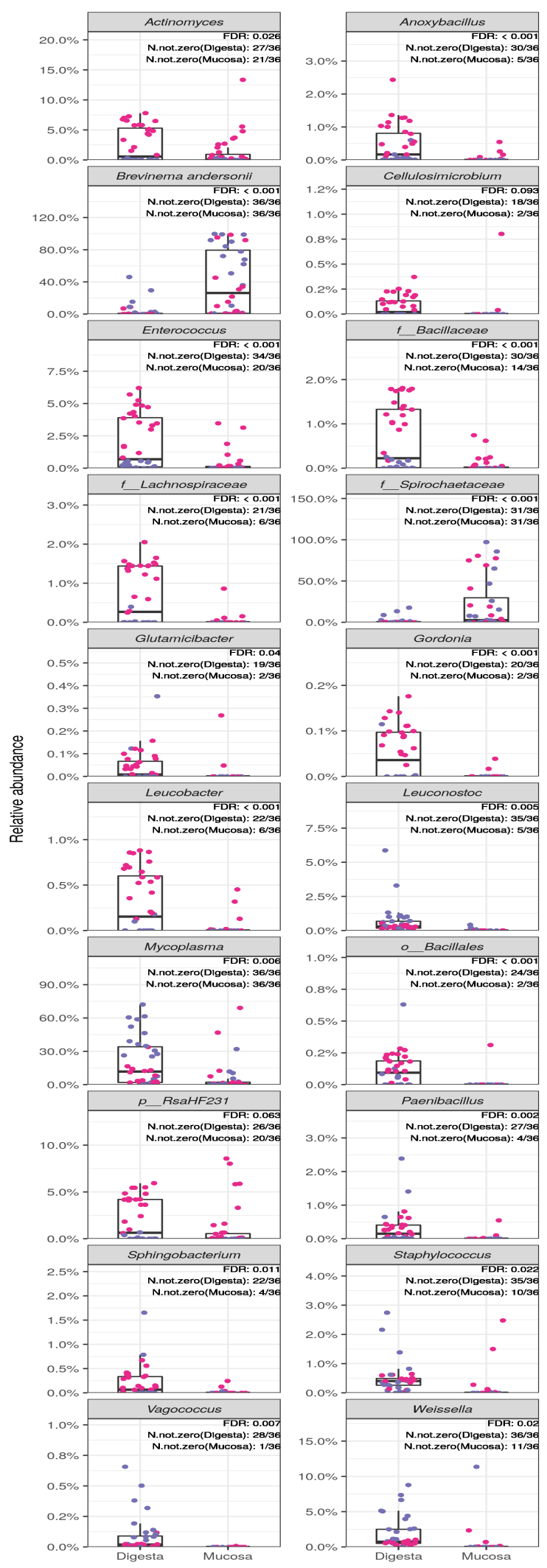

Diet - REF - IM
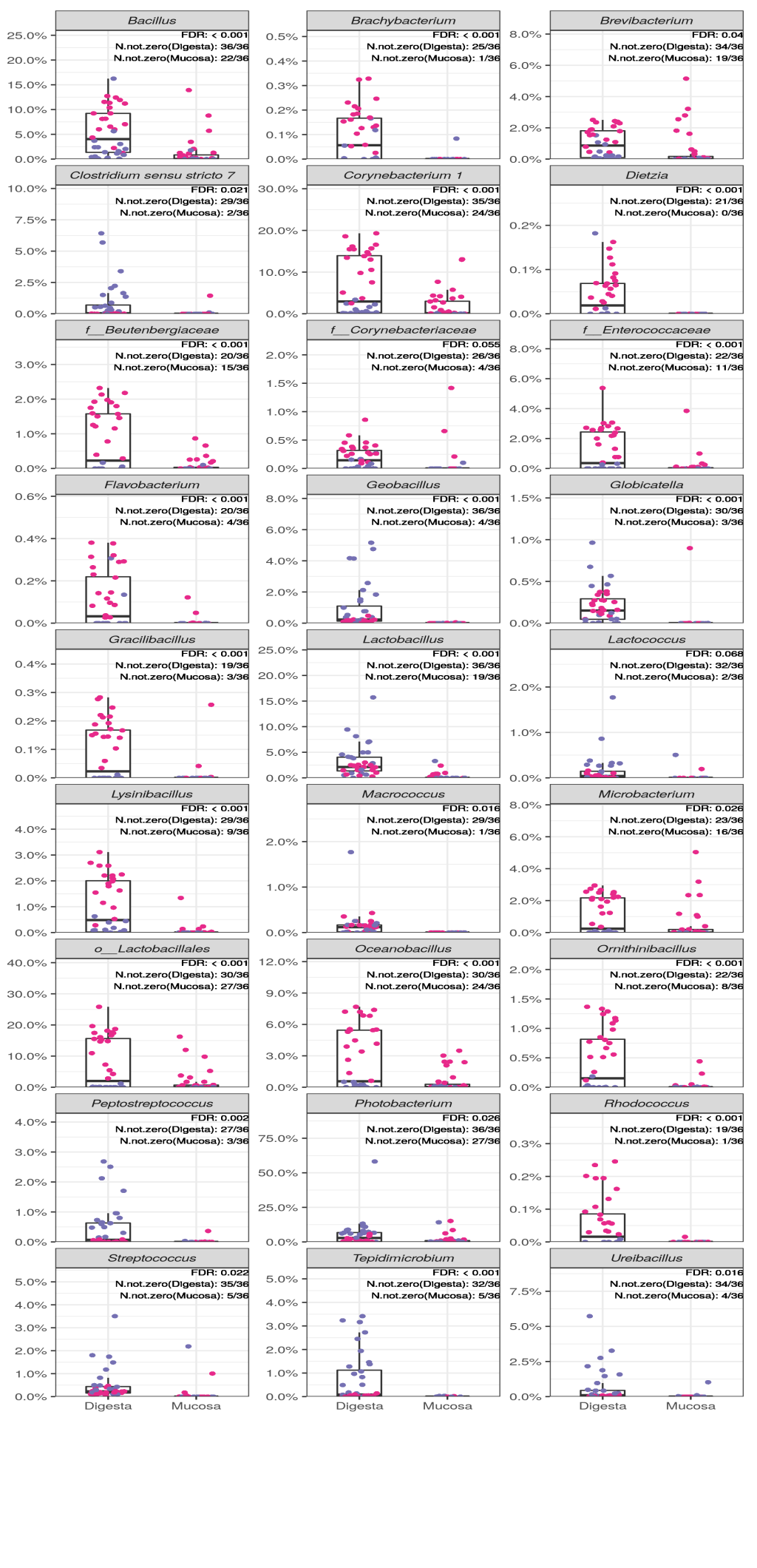

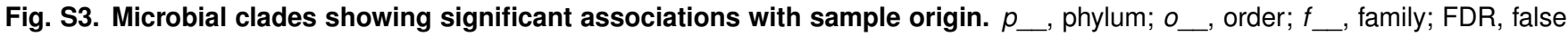
discovery rate; N.not.zero, number of non-zero obsetarvations; REF, reference diet; IM, insect meal diet. 
bioRxiv preprint doi: https://doi.org/10.1101/2020.05.08.083899; this version posted May 24, 2020. The copyright holder for this preprint (which was not certified by peer review) is the author/funder, who has granted bioRxiv a license to display the preprint in perpetuity. It is made available under aCC-BY-ND 4.0 International license.

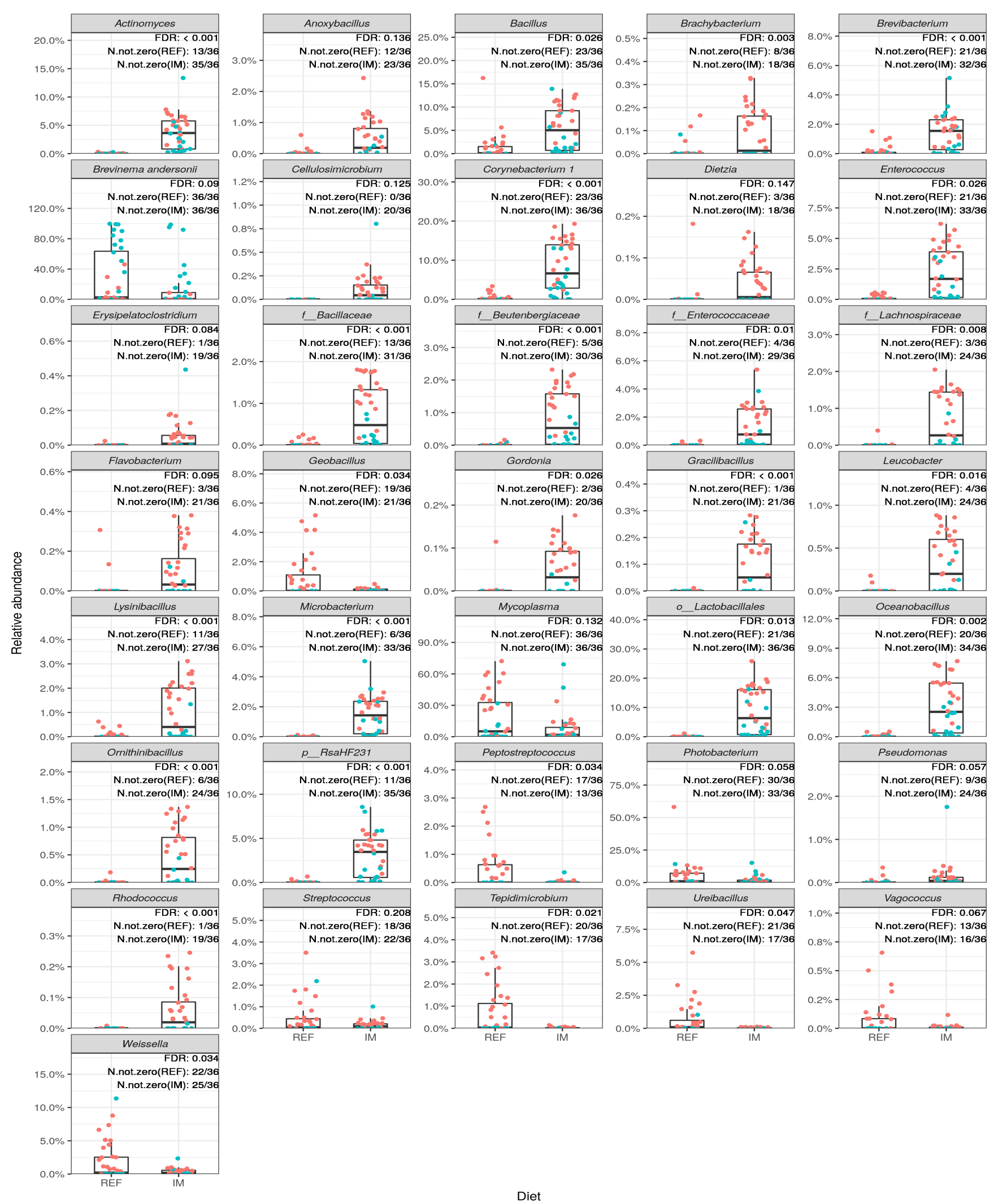


rate; N.not.zero, number of non-zero observations; REF, reference diet; IM, insect meal diet. 
bioRxiv preprint doi: https://doi.org/10.1101/2020.05.08.083899; this version posted May 24, 2020. The copyright holder for this preprint (which was not certified by peer review) is the author/funder, who has granted bioRxiv a license to display the preprint in perpetuity. It is made available under aCC-BY-ND 4.0 International license.

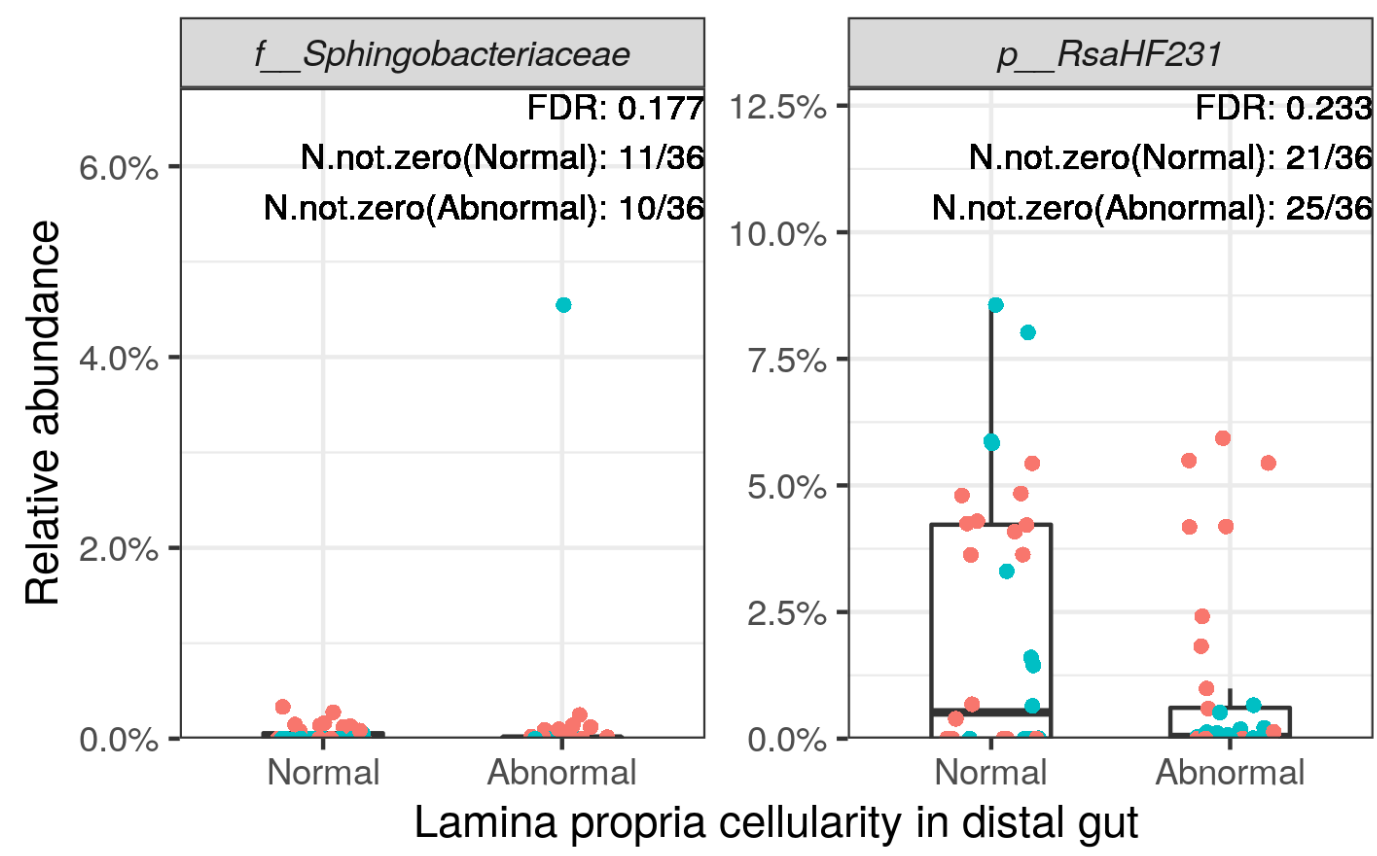

Sample origin

- Digesta

- Mucosa

Fig. S5. Microbial clades showing significant associations with histological scores on lamina propria cellularity in the distal intestine. $p_{\ldots}$, phylum; $f_{\text {_ }}$, family; FDR, false discovery rate; N.not.zero, number of non-zero observations. 
bioRxiv preprint doi: https://doi.org/10.1101/2020.05.08.083899; this version posted May 24, 2020. The copyright holder for this preprint (which was not certified by peer review) is the author/funder, who has granted bioRxiv a license to display the preprint in perpetuity. It is made available under aCC-BY-ND 4.0 International license.
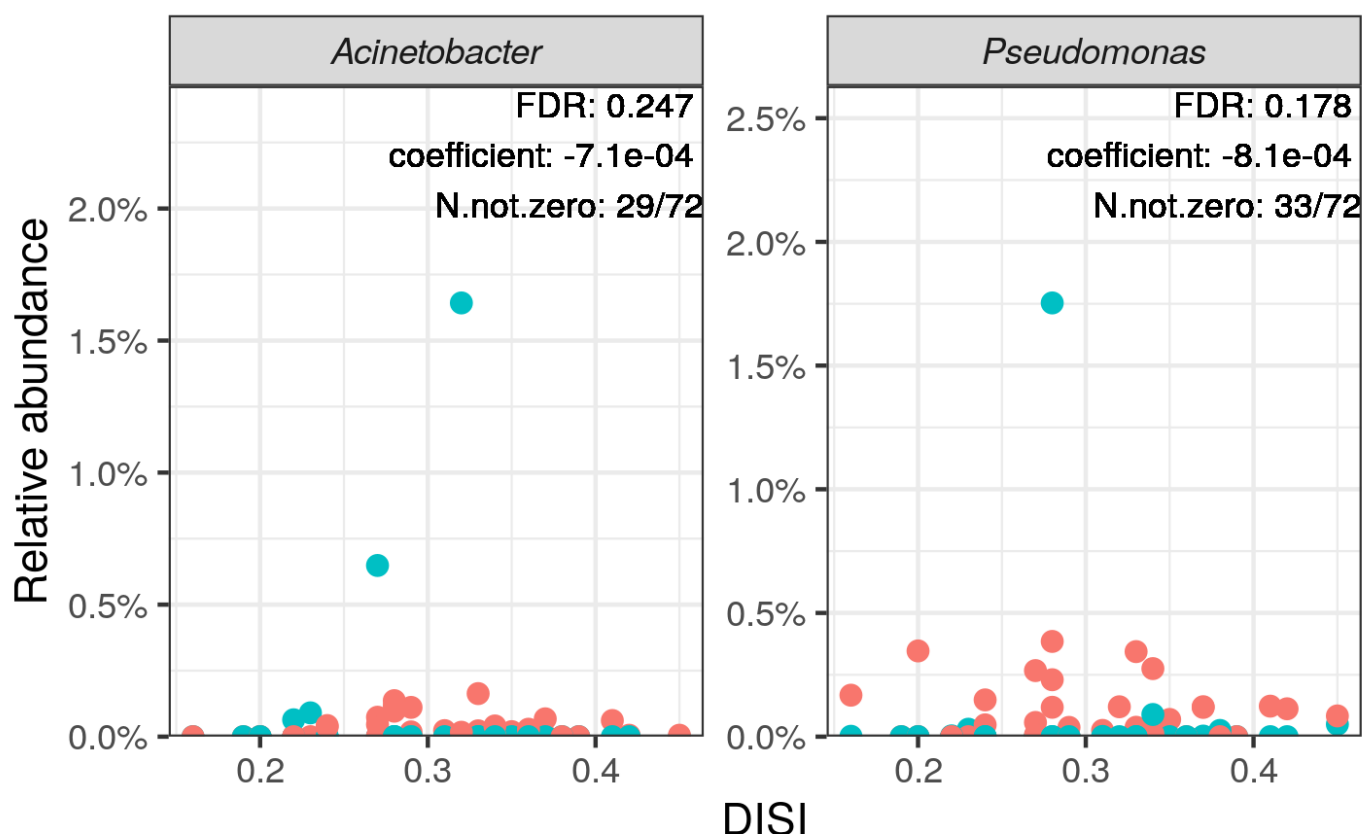

Sample origin

- Digesta

- Mucosa

Fig. S6. Microbial clades showing significant associations with distal intestine somatic index (DISI). FDR, false discovery rate; N.not.zero, number of non-zero observations. 
bioRxiv preprint doi: https://doi.org/10.1101/2020.05.08.083899; this version posted May 24, 2020. The copyright holder for this preprint (which was not certified by peer review) is the author/funder, who has granted bioRxiv a license to display the preprint in perpetuity. It is made available under aCC-BY-ND 4.0 International license.
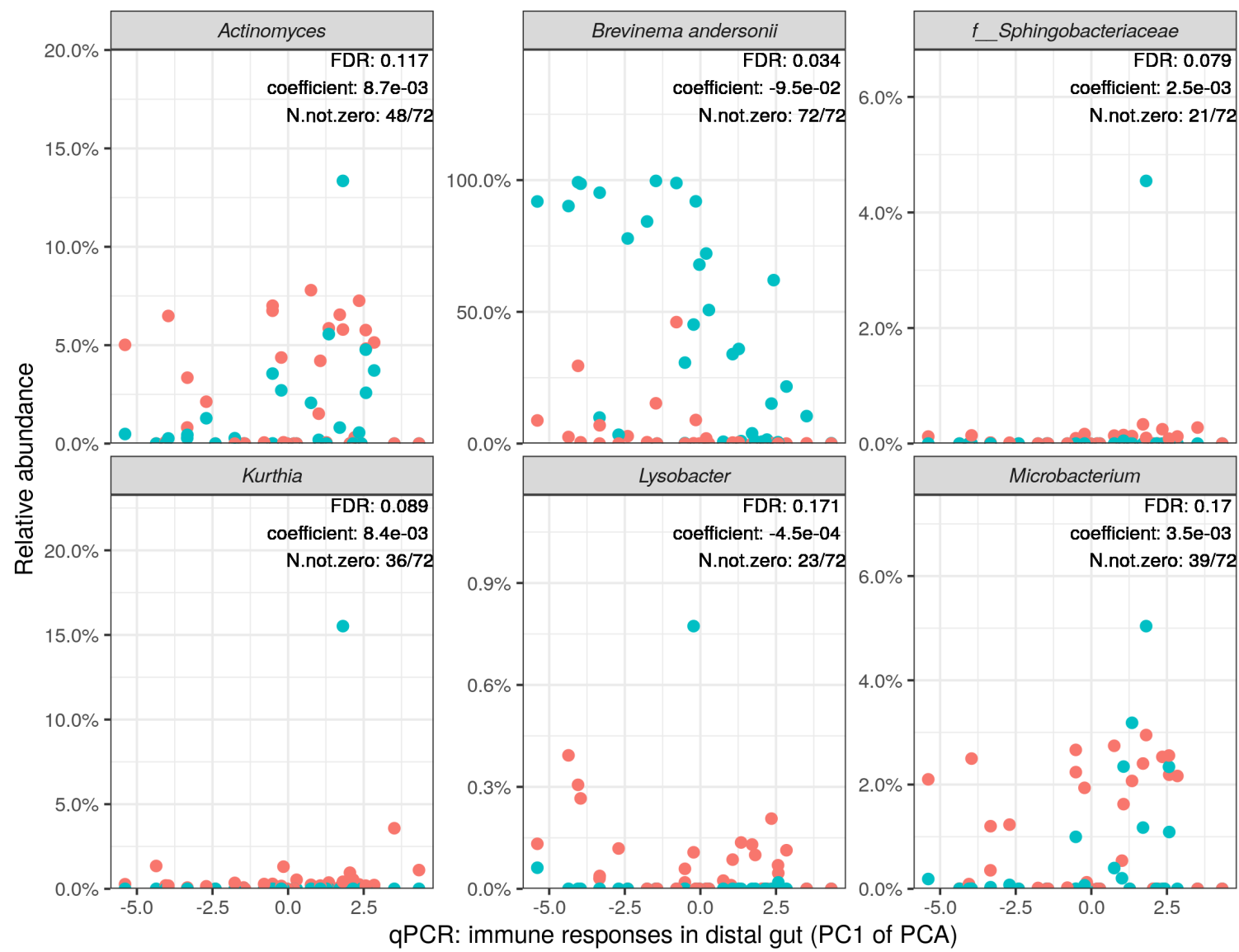

Sample origin

- Digesta

- Mucosa

Fig. S7. Microbial clades showing significant associations with immune gene expressions in the distal intestine. Since the expression levels of immune genes were highly correlated, we ran a principle component analysis (PCA) and used the first principle component (PC1) for the association testing to avoid multicollinearity and reduce the number of association testing. Note that the expression levels of immune genes decrease as the PC1 increases from left to right. Hence, a positive correlation coefficient denotes a negative association between the microbial clade and immune gene expressions, and vice versa. $f_{\text {_ }}$, family; FDR, false discovery rate; N.not.zero, number of non-zero observations. 
bioRxiv preprint doi: https://doi.org/10.1101/2020.05.08.083899; this version posted May 24, 2020. The copyright holder for this preprint (which was not certified by peer review) is the author/funder, who has granted bioRxiv a license to display the preprint in perpetuity. It is made available under aCC-BY-ND 4.0 International license.

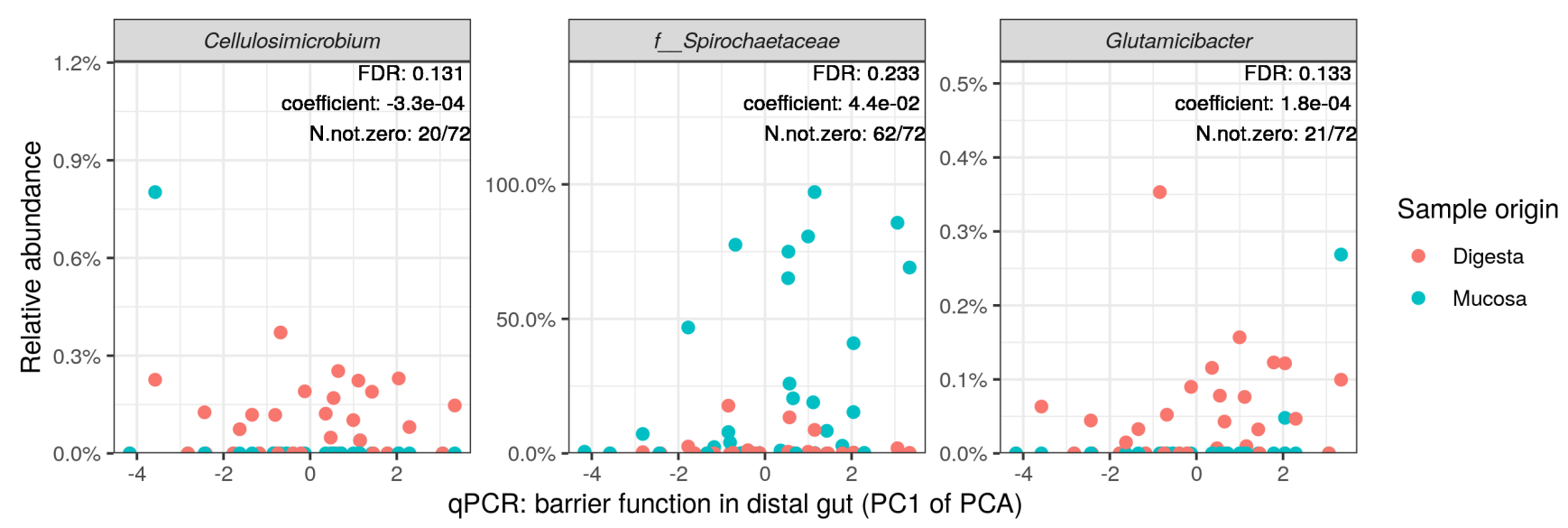

Fig. S8. Microbial clades showing significant associations with expressions of barrier function related genes in the distal intestine. Since the expression levels of barrier function related genes were highly correlated, we ran a principle component analysis (PCA) and used the first principle component (PC1) for the association testing to avoid multicollinearity and reduce the number of association testing. Note that the expression levels of barrier function related genes decrease as the PC1 increases from left to right. Hence, a positive correlation coefficient denotes a negative association between the microbial clade and barrier function related gene expressions, and vice versa. $f_{\ldots}$, family; FDR, false discovery rate; N.not.zero, number of non-zero observations. 